NBER WORKING PAPER SERIES

\title{
LIQUIDITY RISK AND EXPECTED STOCK RETURNS
}

\author{
Lubos Pastor \\ Robert F. Stambaugh \\ Working Paper 8462 \\ http://www.nber.org/papers/w8462 \\ NATIONAL BUREAU OF ECONOMIC RESEARCH \\ 1050 Massachusetts Avenue \\ Cambridge, MA 02138 \\ September 2001
}

Research support from the Center for Research in Security Prices is gratefully acknowledged (Pastor). Comments from Simon Gervais, Andrew Metrick, and Hans Stoll are appreciated. The views expressed herein are those of the authors and not necessarily those of the National Bureau of Economic Research.

(C) 2001 by Lubos Pastor and Robert F. Stambaugh. All rights reserved. Short sections of text, not to exceed two paragraphs, may be quoted without explicit permission provided that full credit, including $(\subset$ notice, is given to the source. 
Liquidity Risk and Expected Stock Returns

Lubos Pastor and Robert F. Stambaugh

NBER Working Paper No. 8462

September 2001

JEL No. G12

\begin{abstract}
$\underline{\text { ABSTRACT }}$
This study investigates whether market-wide liquidity is a state variable important for asset pricing. We find that expected stock returns are related cross-sectionally to the sensitivities of returns to fluctuations in aggregate liquidity. Our monthly liquidity measure, an average of individual-stock measures estimated with daily data, relies on the principle that order flow induces greater return reversals when liquidity is lower. Over a 34-year period, the average return on stocks with high sensitivities to liquidity exceeds that for stocks with low sensitivities by $7.5 \%$ annually, adjusted for exposures to the market return as well as size, value, and momentum factors.
\end{abstract}

\author{
Lubos Pastor \\ Graduate School of Business \\ University of Chicago \\ 1101 E. $58^{\text {th }}$ Street \\ Chicago, IL 60637 \\ lubos.pastor@gsb.uchicago.edu
}

Robert F. Stambaugh Finance Department The Wharton School University of Pennsylvania Philadelphia, PA 19104-6367 and NBER stambaugh@wharton.upenn.edu 


\section{Introduction}

In standard asset pricing theory, expected stock returns are related cross-sectionally to returns' sensitivities to state variables with pervasive effects on consumption and investment opportunities. The basic intuition is that a security whose lowest returns tend to accompany unfavorable shifts in quantities affecting an investor's overall welfare must offer additional compensation to the investor for holding that security. Liquidity appears to be a good candidate for a priced state variable. It is often viewed as important for investment decisions, and recent studies find that fluctuations in various measures of liquidity are correlated across stocks. ${ }^{1}$ This empirical study investigates whether market-wide liquidity is indeed priced. That is, we ask whether cross-sectional differences in expected stock returns are related to the sensitivities of returns to fluctuations in aggregate liquidity. ${ }^{2}$

Liquidity is a broad and elusive concept that generally denotes the ability to trade large quantities quickly, at low cost, and without moving the price. We focus on an aspect of liquidity associated with temporary price fluctuations induced by order flow. Our monthly aggregate liquidity measure is a cross-sectional average of individual-stock liquidity measures. Each stock's liquidity in a given month, estimated using that stock's within-month daily returns and volume, represents the average effect that a given volume on day $d$ has on the return for day $d+1$, when the volume is given the same sign as the return on day $d$. The basic idea is that, if signed volume is viewed roughly as "order flow," then lower liquidity is reflected in a greater tendency for order flow in a given direction on day $d$ to be followed by a price change in the opposite direction on day $d+1$. Essentially, lower liquidity corresponds to stronger volume-related return reversals, and in this respect our liquidity measure follows the same line of reasoning as the model and empirical evidence presented by Campbell, Grossman, and Wang (1993). They find that returns accompanied by high volume tend to be reversed more strongly, and they explain how this result is consistent with a model in which some investors are compensated for accommodating the liquidity demands of others.

\footnotetext{
${ }^{1}$ Chordia, Roll, and Subrahmanyam (2000a), Hasbrouck and Seppi (2000), Huberman and Halka (1999), and Lo and Wang (2000) empirically analyze the systematic nature of liquidity. Eisfeldt (2001) develops a model in which endogenous fluctuations in liquidity are correlated with real fundamentals such as productivity and investment.

${ }^{2}$ The standard models relating securities' expected returns to their state-variable sensitivities, such as Merton (1973) and Cox, Ingersoll, and Ross (1985), are developed under an assumption of perfectly liquid markets. Deriving exact analytical predictions in settings with some degree of illiquidity that fluctuates commonly across securities is a task the theoretical literature still pursues. Nevertheless, the basic intuition underlying the standard theory seems relevant to that more general setting. Holmström and Tirole (2001) develop a model in which a security's expected return is related to its covariance with aggregate liquidity. Unlike standard models, their model assumes risk-neutral consumers and is driven by liquidity demands at the corporate level.
} 
We find that stocks' "liquidity betas," their sensitivities to innovations in aggregate liquidity, play a significant role in asset pricing. Stocks with higher liquidity betas exhibit higher expected returns. In particular, from 1966-99, a spread between the top and bottom deciles of predicted liquidity betas produces an abnormal return ("alpha") of $7.5 \%$ per year with respect to a model that accounts for sensitivities to four other factors: the market, size, and value factors of Fama and French (1993) and a momentum factor. The alpha with respect to just the three Fama-French factors is over 9\% per year. The results are both statistically and economically significant, and similar results occur in both halves of the overall 34-year period.

This study investigates whether expected returns are related to systematic liquidity risk in returns, as opposed to liquidity per se. The latter's relation to expected stock returns has been investigated by numerous empirical studies, including Amihud and Mendelson (1986), Brennan and Subrahmanyam (1996), Brennan, Chordia, and Subrahmanyam (1998), Datar, Naik, and Radcliffe (1998), and Fiori (2000). ${ }^{3}$ Using a variety of liquidity measures, these studies generally find that less liquid stocks have higher average returns. Amihud (2000) and Jones (2000) document the presence of a time-series relation between their measures of market liquidity and expected market returns. Instead of investigating liquidity as a characteristic that is relevant for pricing, this study entertains market-wide liquidity as a state variable that affects expected stock returns because its innovations have effects that are pervasive across common stocks. The potential usefulness of such a perspective is recognized by Chordia, Roll, and Subrahmanyam (2000a, 2000b).

Chordia, Subrahmanyam, and Anshuman (2000) find a significant cross-sectional relation between stock returns and the variability of liquidity, where liquidity is proxied by measures of trading activity such as volume and turnover. The authors report that stocks with more volatile liquidity have lower expected returns, an unexpected result. Liquidity risk in that study is measured as firm-specific variability in liquidity. Our paper focuses on systematic liquidity risk in returns and finds that stocks whose returns are more exposed to market-wide liquidity fluctuations command higher expected returns.

Section 2 explains the construction of the liquidity measure and briefly describes some of its empirical features. The sharpest troughs in market-wide liquidity occur in months easily identified with significant financial and economic events, such as the $1987 \mathrm{crash}$, the beginning of the 1973 oil embargo, and the 1998 collapse of Long Term Capital Manage-

\footnotetext{
${ }^{3}$ Theoretical studies that investigate the relation between liquidity and asset prices include Amihud and Mendelson (1986), Constantinides (1986), Heaton and Lucas (1996), Vayanos (1998), Huang (2001), and Lo, Mamaysky, and Wang (2001), among others.
} 
ment (LTCM). Moreover, in months of large liquidity drops, stock returns are negatively correlated with fixed-income returns, in contrast to other months. This observation seems consistent with "flight-to-quality" effects. We also find significant commonality across stocks in our monthly liquidity measure. That result, in accord with the high-frequency evidence of previous studies, enhances the prospect that market-wide liquidity could be a priced state variable.

Section 3 presents the asset pricing investigation. We find that stocks' liquidity betas can be predicted not only by their simple historical estimates but by other variables as well. In each year, we sort stocks by their predicted liquidity betas and form ten portfolios. This procedure yields a substantial spread in the estimated post-formation liquidity betas as well as the large spread in abnormal returns reported above. Sorting stocks on their historical liquidity betas alone produces results that are slightly less strong but still significant. A sort

on firm size reveals that stocks of the smallest firms tend to have high liquidity betas as well as significantly positive alphas with respect to the four-factor model.

Section 4 provides an investment perspective on liquidity risk by examining the degree to which spreads between stocks with high and low liquidity risk expand the mean-variance opportunity set. In an investment universe that also includes the market portfolio and spreads based on size, value, and momentum, we find that liquidity-risk spreads receive substantial weight in the portfolio with the highest ex post Sharpe ratio. The importance of the momentum spread in that portfolio is especially reduced as compared to a universe without a liquidity-risk spread. Moreover, an equally weighted liquidity-risk spread reduces momentum's alpha by half in the overall 34-year period and eliminates it completely (driving it to a small negative value) in the more recent 17 -year subperiod from 1983-99. Section 5 briefly reviews our conclusions and suggests directions for future research.

\section{Market-Wide Liquidity}

\subsection{Constructing a Measure}

Liquidity has many dimensions. This study focuses on a dimension associated with temporary price changes accompanying order flow. For each month from July 1962 through December 1999, we construct a market liquidity measure as the equally weighted average of the liquidity measures of individual stocks on the NYSE and AMEX, using daily data within 
the month. ${ }^{4}$ Specifically, the liquidity measure for stock $i$ in month $t$ is the ordinary-leastsquares (OLS) estimate of $\gamma_{i, t}$ in the regression,

$$
r_{i, d+1, t}^{e}=\theta_{i, t}+\phi_{i, t} r_{i, d, t}+\gamma_{i, t} \operatorname{sign}\left(r_{i, d, t}^{e}\right) \cdot v_{i, d, t}+\epsilon_{i, d+1, t}, \quad d=1, \ldots, D,
$$

where quantities are defined as follows:

$r_{i, d, t}$ : the return on stock $i$ on day $d$ in month $t$,

$r_{i, d, t}^{e}: \quad r_{i, d, t}-r_{m, d, t}$, where $r_{m, d, t}$ is the return on the CRSP value-weighted market return on day $d$ in month $t$, and

$v_{i, d, t}$ : the dollar volume for stock $i$ on day $d$ in month $t$.

A stock's liquidity estimate is included in a given month only if there are at least 15 consecutive observations with which to estimate the above regression (i.e., $D \geq 15$ ); stocks with share prices less than $\$ 5$ and greater than $\$ 1000$ are excluded; and volume is measured in millions of dollars.

The basic idea is that "order flow," constructed here simply as volume signed by the contemporaneous return on the stock in excess of the market, should be accompanied by a return that one expects to be partially reversed in the future if the stock is not perfectly liquid. We assume that the greater is that expected reversal for a given dollar volume, the lower is the stock's liquidity. That is, one would expect $\gamma_{i, t}$ to be negative in general and larger in absolute magnitude when liquidity is lower. ${ }^{5}$ Viewing volume-related return reversals as arising from liquidity effects is motivated by Campbell, Grossman, and Wang (1993). Those authors present a model in which risk-averse "market makers," defined in the general sense of Grossman and Miller (1988), accommodate order flow from liquiditymotivated traders and are compensated with higher expected return (by buying at a low price or selling at a high one). The greater the order flow, the greater the compensation, so this liquidity-induced effect on expected future return is larger when current volume is high. Campbell, Grossman, and Wang present empirical evidence consistent with this argument.

As illustrated below, the estimates of the liquidity measure $\gamma_{i, t}$ are typically negative, although there are months in which the average estimate is positive. The preponderance of

\footnotetext{
${ }^{4}$ All of the individual-stock return and volume data used in the study are obtained from the Center for Research in Security Prices (CRSP) at the University of Chicago. We exclude NASDAQ in constructing the aggregate liquidity measure, because NASDAQ returns and volume data are available from CRSP for only part of this period (beginning in 1982). Also, reported volumes on NASDAQ include inter-dealer trades, unlike the volumes reported on the NYSE and the AMEX.

${ }^{5}$ An alternative class of liquidity measures is based on a positive contemporaneous relation between returns and order flow. Typically, these measures are estimated with intraday transactions data, and the volume for a transaction is signed by comparing the transaction price to the bid-ask midpoint. See, for example, Hasbrouck (1991), Foster and Viswanathan (1993), and Brennan and Subrahmanyam (1996).
} 
negative values is consistent with the basic intuition underlying our liquidity measure, but it must be recognized that the measure abstracts from other potential roles that volume can play in the relation between current and lagged return. For example, Llorente, Michaely, Saar, and Wang (2001) explain that asymmetric information (not considered by Campbell, Grossman and Wang, 1993) can weaken the volume-related reversal effect and even produce volume-related continuations in returns on stocks for which information-motivated trading is sufficiently important. Using daily data, the authors report empirical evidence consistent with that prediction. Other related evidence is reported by Lee and Swaminathan (1998), who conclude that momentum effects in monthly returns are stronger for stocks with high recent volume.

The precise specification of the regression in (1) is somewhat arbitrary, as is any liquidity measure. We use $r_{i, d, t}^{e}$, the return in excess of the market, both as the dependent variable as well as to sign volume, in order to better isolate the individual-stock effect of volume-related return reversals. We also include the lagged stock return as a second independent variable with the intention of capturing lagged-return effects that are not volume-related, such as reversals due to a minimum tick size. For that purpose we use the total return $r_{i, d, t}$ instead of the return in excess of the market simply to have this second variable be somewhat less correlated with the variable whose coefficient we take as the liquidity measure (since we use $r_{i, d, t}^{e}$ to sign volume).

The use of signed volume as a predictor of future return can be motivated a bit more formally using the equilibrium model of Campbell, Grossman, and Wang (1993). In their model, the stock's excess return $Q_{t}$ and order flow $\Delta_{t}$ are jointly normal, along with $Q_{t+1}$, and the regression relating expected future return to current return and volume $V_{t}\left(=\left|\Delta_{t}\right|\right)$ is given by a relation of the form

$$
\mathrm{E}\left(Q_{t+1} \mid Q_{t}, V_{t}\right)=\phi_{1} Q_{t}-\phi_{2} \tanh \left(\phi_{3} V_{t} Q_{t}\right) V_{t}
$$

where $\phi_{2}<0$ and $\phi_{3}<0$. As the correlation between $Q_{t}$ and $\Delta_{t}$ increases, (2) becomes well approximated by

$$
\mathrm{E}\left(Q_{t+1} \mid Q_{t}, V_{t}\right)=\phi_{1} Q_{t}+\phi_{2} \operatorname{sign}\left(Q_{t}\right) V_{t}
$$

which is roughly analogous to (1). ${ }^{6}$ To the extent that order flow plays an important role in

\footnotetext{
${ }^{6}$ Equation (2) relies on a result given in Wang (1994). It is straightforward to show that Wang's equation B.6 allows (2) to be restated as

$$
E\left(Q_{t+1} \mid Q_{t}, V_{t}\right)=\phi_{1} Q_{t}+\phi_{2} \tanh \left[\left(\frac{\rho}{1-\rho^{2}}\right)\left(\frac{Q_{t}}{\sigma_{Q}}\right)\left(\frac{V_{t}}{\sigma_{\Delta}}\right)\right] V_{t}
$$

where $\rho$ is the correlation between $Q_{t}$ and $\Delta_{t}$, and $\sigma_{Q}$ and $\sigma_{\Delta}$ are the standard deviations of those variables.
} 
determining high-frequency return variation, a conjecture that seems plausible, we see that the model of Campbell, Grossman, and Wang gives some justification for the use of signed volume. Of course, their model of a single-stock economy with continuous price variables (no minimum tick) is only suggestive when applied to our empirical setting, but the intuition underlying their model corresponds to our interpretation of $\gamma_{i, t}$ as a liquidity measure.

Although the OLS slope coefficient $\hat{\gamma}_{i, t}$ is an imprecise estimate of a given stock's $\gamma_{i, t}$, the market-wide average liquidity in month $t$ is estimated more precisely. The disturbances in (1) are less than perfectly correlated across stocks (recall that the dependent variable is the return in excess of the market). Thus, as the number of stocks, $N$, grows large, the true unobserved average $\gamma_{t}=(1 / N) \sum_{i=1}^{N} \gamma_{i, t}$ becomes more precisely estimated by

$$
\hat{\gamma}_{t}=(1 / N) \sum_{i=1}^{N} \hat{\gamma}_{i, t}
$$

We construct the above market-wide measure for each month from August 1962 through December 1999 using all NYSE and AMEX stocks with available data, and $N$ ranges from 939 to 2,121 . The raw series of $\hat{\gamma}_{t}$ 's is subject to the upward trend in dollar values (and volumes) over the period, so the values of $\hat{\gamma}_{t}$ tend to be smaller in magnitude later in the period. To obtain more homogeneity over time, we construct the scaled series $\left(m_{t} / m_{1}\right) \hat{\gamma}_{t}$, where $m_{t}$ is the total dollar value at the end of month $t-1$ of the stocks included in the average in month $t$, and month 1 corresponds to August 1962. This scaled series is plotted in Figure 1.

The scaled liquidity series has a first-order serial correlation of 0.22 . To construct innovations in liquidity, we first form the scaled monthly difference,

$$
\Delta \hat{\gamma}_{t}=\left(\frac{m_{t}}{m_{1}}\right)\left(\hat{\gamma}_{t}-\hat{\gamma}_{t-1}\right)
$$

and then regress $\Delta \hat{\gamma}_{t}$ on its lag as well as the lagged value of the scaled level series:

$$
\Delta \hat{\gamma}_{t}=a+b \Delta \hat{\gamma}_{t-1}+c\left(\frac{m_{t}}{m_{1}}\right) \hat{\gamma}_{t-1}+u_{t}
$$

This regression produces residuals that appear serially uncorrelated. The innovation in liquidity, $\mathcal{L}_{t}$, is taken as the fitted residual divided by 100 :

$$
\mathcal{L}_{t}=\frac{1}{100} \hat{u}_{t}
$$

Note that as $\rho \rightarrow 1, \tanh \left[\left(\frac{\rho}{1-\rho^{2}}\right)\left(\frac{Q_{t}}{\sigma_{Q}}\right)\left(\frac{V_{t}}{\sigma_{\Delta}}\right)\right]$ converges in distribution to $\operatorname{sign}\left(Q_{t}\right)$, since $V_{t} \geq 0$ and $\tanh (x)$ approaches $1(-1)$ as $x \rightarrow \infty(-\infty)$. 
The arbitrary scaling by 100 simply produces more convenient magnitudes of the liquidity betas reported in the next section.

Our liquidity measure relies on a large cross-section of stocks and yields a monthly series spanning more than 37 years. As such, the series seems well suited for this study's focus on liquidity risk and asset pricing. Aggregate stock-market liquidity is measured in a variety of alternative ways by recent studies that explore other interesting issues. Those studies include Amihud (2000), Chordia, Roll, and Subrahmanyam (2000a, 2000b, 2001), Jones (2000), and Lo and Wang (2000). Chordia, Roll, and Subrahmanyam form daily time series of various measures of liquidity (such as depth and quoted and effective bid-ask spreads) and trading activity (such as dollar volume and order imbalance), averaged across NYSE stocks over the period 1988 through 1998. Jones collects an annual time series of average quoted bid-ask spreads on the stocks in the Dow Jones index, covering the period of 1898 through 1998. Amihud constructs an annual aggregate liquidity series for the period of 1963 through 1997 by averaging across NYSE stocks the ratios of average absolute price change to trading volume. Lo and Wang form a weekly series of average turnover across NYSE and AMEX stocks from July 1962 to December 1996.

\subsection{Empirical Features of the Liquidity Measure}

Perhaps the most salient features of the liquidity series plotted in Figure 1 are its occasional downward spikes, indicating months with especially low estimated liquidity. Many of these spikes occur during market downturns, consistent with the evidence in Chordia, Roll, and Subrahmanyam (2000b) and Jones (2000), who use different liquidity measures. Chordia, Roll, and Subrahmanyam observe that their liquidity measures plummet in down markets, and Jones finds that his average-spread measure exhibits frequent sharp spikes that often coincide with market downturns.

The largest downward spike in our measure of aggregate liquidity occurs in October 1987, the month of the stock-market crash. Grossman and Miller (1988) argue that both spot and futures stock markets were "highly illiquid" on October 19, the day of the crash, and Amihud, Mendelson, and Wood (1990) contend that the crash occured in part because of a rise in market illiquidity during and before October 19. The second largest spike is in November 1973, the first full month of the mideast oil embargo. Estimated liquidity is generally low in the early 1970s, again consistent with the evidence in Jones (2000). The third largest negative value is in September 1998, when liquidity is widely perceived to have dried up due 
to the LTCM collapse and the recent Russian debt crisis. $^{7}$ The next largest spike occurs in May 1970, a month of significant domestic political unrest. ${ }^{8}$ There is obviously a risk in pushing such anecdotal analysis very far, but a drop in stock-market liquidity during these months seems at least plausible.

The monthly innovation in liquidity, $\mathcal{L}_{t}$, has a correlation of 0.36 with the returns on both the value-weighted and equally weighted NYSE-AMEX indexes, constructed by CRSP. This result goes in the same direction as that reported by Chordia, Roll, and Subrahmanyam (2000b), who find a positive association at a daily frequency between stock returns and changes in other market-wide liquidity measures. As mentioned earlier, the downward spikes in our liquidity series often coincide with market downturns, and this observation is confirmed by comparing correlations between $\mathcal{L}_{t}$ and the value-weighted market return for months in which that return is negative versus positive. The correlation is 0.52 in negative-return months but only 0.03 in positive-return months, and the difference between the liquidityreturn relation in these two subsamples is statistically significant. ${ }^{9}$ The simple correlation between $\mathcal{L}_{t}$ and stock-market returns is larger than those between $\mathcal{L}_{t}$ and other factors typically included in empirical asset pricing studies. In particular, $\mathcal{L}_{t}$ 's correlations with SMB and HML, the size and value factors constructed by Fama and French (1993), are 0.23 and $-0.12 .{ }^{10}$ Recall that SMB is the difference in returns between small and large firms, while HML is the return difference between stocks with high and low book-to-market ratios (i.e., value minus growth). The correlation between $\mathcal{L}_{t}$ and a momentum factor is only 0.01 . The inclusion of momentum as an asset pricing factor, here and in other studies, is motivated by the evidence in Jegadeesh and Titman (1993) that ranking stocks by performance over the past year produces abnormal returns. ${ }^{11}$

${ }^{7}$ The Economist magazine (September 25, 1999) writes that "In August 1998, after the Russian government had defaulted on its debts, liquidity suddenly evaporated from many financial markets, causing asset prices to plunge." The article also asserts that "The possibility that liquidity might disappear from a market ... is a big source of risk to an investor."

${ }^{8}$ On April 30, President Nixon announced the invasion of Cambodia and the need to draft 150,000 more soldiers, the Kent State and Jackson State shootings occurred on May 4 and May 14, and nearly 500 colleges and universities closed that month due to anti-war protests.

${ }^{9}$ We run the regression,

$$
\mathcal{L}_{t}=a+b R_{S, t}+c D_{t} R_{S, t}+e_{t},
$$

where $R_{S, t}$ is the market return and $D_{t}=1$ if $R_{S, t}>0$ and zero otherwise. The estimate of $b$ is 1.01 with a t-statistic of 9.7, and the estimate of $\mathrm{c}$ is -0.99 with a t-statistic of -6.2.

${ }^{10}$ We are grateful to Ken French for supplying the Fama-French factors.

${ }^{11}$ To construct the momentum factor in month $t$, which we denote as MOM, all stocks in the CRSP file with return histories back to at least month $t-12$ are ranked at the end of month $t-1$ by their cumulative returns over months $t-12$ through $t-2$, and MOM is the payoff on a spread consisting of a $\$ 1$ long position in an equally weighted portfolio of the top decile of the stocks in that ranking and a corresponding $\$ 1$ short position in the bottom decile. This particular specification is the same as the "12-2" portfolio in Fama and French (1996). 
To describe further the nature of months with exceptionally low liquidity, we note that a kind of "flight to quality" effect appears in such months. That is, months in which liquidity drops severely tend to be months in which stocks and fixed-income assets move in opposite directions. Table 1 reports correlations between the monthly return on the CRSP valueweighted NYSE-AMEX index $\left(R_{S, t}\right)$ and three fixed-income variables: minus the change in the rate on one-month Treasury bills $\left(-\Delta R_{f, t}\right)$, the return on long-term government bonds $\left(R_{G B, t}\right)$, and the return on long-term corporate bonds $\left(R_{C B, t}\right) .{ }^{12}$ The first row reports the correlations across all months, and the next two rows report correlations in subsamples split according to the values of $\mathcal{L}_{t}$. The second row of Table 1 shows the correlation between $R_{S, t}$ and the other variables during the 14 months in which $\mathcal{L}_{t}$ is at least 2 standard deviations below its mean. The correlations between stock returns and the three fixed-income series during those months are negative, in contrast to the correlations during the remaining months, and the bootstrap p-values indicate that those differences are significant at levels of either $5 \%$ (for the bond returns) or $10 \%$ (for the T-bill rate change). ${ }^{13}$ The results across both subperiods generally support the inference drawn for the overall period, in that five of the six correlations between $R_{S, t}$ and the fixed-income series are negative in the months of large liquidity drops.

Also shown in Table 1 is the correlation between the stock return $R_{S, t}$ and the change in volume $\mathrm{Vol}_{t}$, defined as the equally weighted average percentage change in monthly dollar volume for NYSE-AMEX stocks. Stock returns are positively correlated with volume changes in all months, but the correlation is negative in months with large liquidity drops, and the bootstrap p-value for the overall period is 0.002 . The subperiod results again support the inference that the correlation is lower in the months of severe liquidity drops. There is no obvious story here, other than perhaps that, in such months, higher volume accompanying a larger liquidity drop is another manifestation of a flight to quality. We also find that, in low liquidity months, the correlation between volume changes and $\mathcal{L}_{t}$ is equal to -0.27 , whereas it equals 0.18 in other months (and in all months). But, again, we do not wish to push the descriptive analysis of the market-wide liquidity series too far. The primary goal of the paper is to investigate whether liquidity is a source of priced systematic risk in stock returns, and we use the series constructed here for that purpose.

An important motive for entertaining a market-wide liquidity measure as a priced state variable is evidence that fluctuations in liquidity exhibit commonality across stocks. Chor-

\footnotetext{
${ }^{12}$ The fixed-income data are obtained from Ibbotson Associates.

${ }^{13}$ The p-values are computed by resampling the original series and then randomly assigning observations to subsamples of the same size as in the reported results.
} 
dia, Roll, and Subrahmanyam (2000a) and Huberman and Halka (1999) find significant commonality in various liquidity measures at a daily frequency, while Hasbrouck and Seppi (2000) find only weak commonality in intraday (15-minute) fluctuations in liquidity. Our stock-by-stock measure $\hat{\gamma}_{i t}$ affords an additional perspective on commonality, since it measures liquidity differently, it is constructed at a monthly frequency, and our sample period is substantially longer. We conduct a simple exploration of commonality in $\hat{\gamma}_{i t}$ across stocks by first sorting all stocks at the end of each year by market value and then assigning them to decile portfolios based on NYSE breakpoints (i.e., each decile has an equal number of NYSE stocks). Each decile portfolio's change in liquidity for a given month is then computed as the cross-sectional average change in the individual-stock measures, and this procedure yields a 1963-1999 monthly series of liquidity changes for each decile. The sample correlation of these series between any two deciles is positive. If the decile series are averaged separately across the odd-numbered and even-numbered deciles, the sample correlation between the two resulting series is 0.56 , and the t-statistic for a test of zero correlation is 14.20 . This commonality in our liquidity measure across stocks enhances the prospect that market-wide liquidity represents a priced source of risk.

\section{Is Liquidity Risk Priced?}

This section investigates whether a stock's expected return is related to the sensitivity of its return to the innovation in aggregate liquidity, $\mathcal{L}_{t}$. That sensitivity, denoted for stock $i$ by its liquidity beta $\beta_{i}^{\mathcal{L}}$, is the slope coefficient on $\mathcal{L}_{t}$ in a multiple regression in which the other independent variables are additional factors considered important for asset pricing. To investigate whether the stock's expected return is related to $\beta_{i}^{\mathcal{L}}$, we follow a straightforward portfolio-based approach to create a universe of assets whose liquidity betas are sufficiently disperse. At the end of each year, starting with 1965, we sort stocks based on their predicted values of $\beta_{i}^{\mathcal{L}}$ and form ten portfolios. The post-formation returns on these portfolios during the next 12 months are linked across years to form a single return series for each decile portfolio. The excess returns on those portfolios are then regressed on return-based factors that are commonly used in empirical asset pricing studies. To the extent that the regression

intercepts, or alphas, differ from zero, $\beta_{i}^{\mathcal{L}}$ explains a component of expected returns not captured by exposures to the other factors.

For the purpose of portfolio formation, we define $\beta_{i}^{\mathcal{L}}$ as the coefficient on $\mathcal{L}_{t}$ in a regression 
that also includes the three factors of Fama and French (1993),

$$
r_{i, t}=\beta_{i}^{0}+\beta_{i}^{\mathcal{L}} \mathcal{L}_{t}+\beta_{i}^{\mathrm{M}} \mathrm{MKT}_{t}+\beta_{i}^{\mathrm{S}} \mathrm{SMB}_{t}+\beta_{i}^{\mathrm{H}} \mathrm{HML}_{t}+\epsilon_{i, t},
$$

where $r_{i, t}$ denotes asset $i$ 's excess return, MKT denotes the excess return on a broad market index, and the other two factors, SMB and HML, are payoffs on long-short spreads constructed by sorting stocks according to market capitalization and book-to-market ratio. This definition of $\beta_{i}^{\mathcal{L}}$ captures the asset's comovement with aggregate liquidity that is distinct from its comovement with other commonly used factors. We allow $\beta_{i}^{\mathcal{L}}$ for any given stock to vary through time, and the predicted values of $\beta_{i}^{\mathcal{L}}$ used to sort stocks are obtained using two methods. The first allows the predicted $\beta_{i}^{\mathcal{L}}$ to depend on the stock's historical least-squares estimate as well as a number of additional stock characteristics observable at the time of the sort. The results using that method, reported in subsection 3.1., reveal large differences in expected returns on $\beta_{i}^{\mathcal{L}}$-sorted portfolios that are unexplained by the other factors. The second method uses only historical betas and is presented to confirm that the first set of results is not driven solely by sorting stocks on the other characteristics that help predict liquidity betas. The results from that method, reported in subsection 3.2., also reveal large and significant differences in alphas on the $\beta_{i}^{\mathcal{L}}$-sorted portfolios. Subsection 3.3 reports results obtained for portfolios formed by sorting stocks on market capitalization.

The portfolio-formation procedure uses data available only as of the formation date, and this requirement applies to the liquidity series as well. Thus, the formation procedure each year begins with a re-estimation of (6) using only the raw liquidity series $\left(\hat{\gamma}_{t}\right)$ available up to that point in time. The historical values of $\mathcal{L}_{t}$ used in that formation year are then recomputed using $(7)$, where $\hat{u}_{t}$ is the fitted residual from that re-estimated regression.

Our analysis covers all stocks traded on the NYSE, AMEX, and NASDAQ that are ordinary common shares (CRSP sharecodes 10 and 11), excluding ADRs, SBIs, certificates, units, REITs, closed-end funds, companies incorporated outside the U.S., and Americus Trust Components. Stocks with prices below $\$ 5$ or above $\$ 1,000$ are also excluded from the portfolio sorts.

\section{1. $\quad$ Sorting by Predicted Liquidity Betas}

\subsubsection{Predicting Liquidity Betas}

We model each stock's liquidity beta as a linear function of observable variables,

$$
\beta_{i, t-1}^{\mathcal{L}}=\psi_{1, i}+\psi_{2, i}^{\prime} Z_{i, t-1} .
$$


The vector $Z_{i, t-1}$ contains seven characteristics: (i) the historical liquidity beta estimated using all data available from months $t-60$ through $t-1$ (if at least 36 months are available), (ii) the average value of $\hat{\gamma}_{i, t}$ from month $t-6$ through $t-1$, (iii) the natural log of the stock's average dollar volume from months $t-6$ through $t-1$, (iv) the cumulative return on the stock from month $t-6$ through $t-1$, (v) the standard deviation of the stock's monthly return from month $t-6$ through $t-1$, (vi) the natural log of the price per share from month $t-1$, and (vii) the natural log of the number of shares outstanding from month $t-1$. (These seven characteristics are listed in Table 2.) The list of characteristics is necessarily arbitrary, although they do possess some appeal ex ante. Historical liquidity beta should be useful if the true beta is fairly stable over time. The average of the stock's $\hat{\gamma}_{i, t}$ and volume can matter if liquidity risk is related to liquidity per se. Stocks with different market capitalization could have different liquidity betas, so we include shares outstanding and stock price, whose product is equal to the stock's market capitalization. The level and variability of recent returns simply allow some role for short-run return dynamics. Each characteristic is "demeaned" by subtracting the time-series average (through month $t-1$ ) of the characteristic's cross-sectional average in each previous month.

Substituting the right-hand side of (9) for $\beta_{i}^{\mathcal{L}}$ in (8), we obtain

$$
r_{i, t}=\beta_{i}^{0}+\beta_{i}^{\mathrm{M}} \mathrm{MKT}_{t}+\beta_{i}^{\mathrm{S}} \mathrm{SMB}_{t}+\beta_{i}^{\mathrm{H}} \mathrm{HML}_{t}+\left(\psi_{1, i}+\psi_{2, i}^{\prime} Z_{i, t-1}\right) \mathcal{L}_{t}+\epsilon_{i, t} .
$$

The above regression for stock $i$ contains 11 independent variables, 7 of which are crossproducts of the elements of $Z_{i, t-1}$ with $\mathcal{L}_{t}$. (This approach to incorporating time-variation in betas follows Shanken, 1990.) To increase precision in the face of the substantial variance in individual-stock returns, we restrict the coefficients $\psi_{1, i}$ and $\psi_{2, i}$ in equation (9) to be the same across all stocks and estimate them using the whole panel of stock returns. Specifically, at the end of each year between 1965 and 1998, we first construct for each stock the historical series of

$$
\epsilon_{i, t}=r_{i, t}-\hat{\beta}_{i}^{\mathrm{M}} \mathrm{MKT}_{t}-\hat{\beta}_{i}^{\mathrm{S}} \mathrm{SMB}_{t}-\hat{\beta}_{i}^{\mathrm{H}} \mathrm{HML}_{t},
$$

where the $\hat{\beta}$ 's are estimated from the regression of the stock's excess returns on the FamaFrench factors and $\mathcal{L}_{t}$, using all data available up to the current year-end. Then we run a pooled time-series cross-sectional regression of $\epsilon_{i, t}$ on the characteristics,

$$
\epsilon_{i, t}=\psi_{0}+\psi_{1} \mathcal{L}_{t}+\psi_{2}^{\prime} Z_{i, t-1} \mathcal{L}_{t}+\nu_{i, t}
$$

again using all data available up to the current year-end. The first year-end considered here is that of 1965, since the data on $\mathcal{L}_{t}$ begin in August 1962, and it seems reasonable to use at least three years of data to conduct the estimation. A stock is excluded for any month in which it has any missing characteristics. 
Table 2 reports the estimated coefficients $\hat{\psi}_{1}$ and $\hat{\psi}_{2}$ from the pooled regression, together with their $t$-statistics. ${ }^{14}$ Results are reported for several periods, each beginning in August 1962 but ending in December of a different year; the estimated coefficients are those used in the ranking at that year-end. Each coefficient is multiplied by the time-series average of the cross-sectional standard deviation of the corresponding de-meaned characteristic. This scaling helps clarify the relative contributions of the individual characteristics to the predicted betas. Historical liquidity beta is the most important determinant of the predicted beta in the longest sample period, used for the most recent ranking in December 1998. The coefficient of $2.30(t=9.97)$ indicates that if a stock's historical liquidity beta is one crosssectional standard deviation above the cross-sectional mean of the historical betas, then the stock's predicted liquidity beta is higher by 2.30 , holding constant the other characteristics and averaging the effect over time. Historical beta is also the most robust determinant of the predicted beta across the different periods. The coefficient on stock price is significantly positive early in the sample, but its effect weakens in the longer period. Volatility enters negatively, again more strongly in the earlier periods. The coefficients on the stock's past return, shares outstanding, and average volume are less stable over time. ${ }^{15}$ The coefficient on the stock's recent average $\hat{\gamma}_{i t}$ is significantly negative in the longest period (and insignificantly negative in the subperiods), suggesting that stocks with lower liquidity (as measured by $\hat{\gamma}_{i t}$ ) tend to be more exposed to aggregate liquidity fluctuations.

\subsubsection{Post-Ranking Portfolio Betas}

At the end of each year, stocks are sorted by their predicted liquidity betas and assigned to ten portfolios. The predicted beta for each stock is calculated from equation (9), using the year-end values of the stock's characteristics along with the values of $\hat{\psi}_{1}$ and $\hat{\psi}_{2}$ estimated using data through the current year-end. Portfolio returns are computed over the following 12 months, after which the estimation/formation procedure is repeated. The post-ranking returns are linked across years, generating a single return series for each decile covering the

\footnotetext{
${ }^{14}$ The $t$-statistics are computed assuming independence of the regression residuals, which are purged of common variation in returns attributable to the three Fama-French factors together with $\mathcal{L}_{t}$.

${ }^{15}$ As mentioned earlier, the trading volume of the NASDAQ stocks is overstated relative to the NYSE/AMEX volume. When the NASDAQ stocks are excluded from the pooled regression, the coefficient on volume remains negative in the first two subperiods and turns insignificantly negative in the overall period. In addition, the results presented in this section lead to similar conclusions about the relation between liquidity risk and expected stock returns. We retain the NASDAQ stocks in the analysis, because their inclusion increases the dispersion of the post-ranking liquidity betas of the portfolios sorted on predicted betas, in line with the purpose of the sorting procedure. Stocks with prices outside the $\$ 5$ - 1000 range are also included in the pooled regression for the same reason: their inclusion increases the spread in the post-ranking betas, even if these stocks are subsequently excluded from the portfolio sorts.
} 
period from January 1966 through December 1999. On average, there are 187 stocks in each portfolio, and no portfolio ever contains fewer than 103 stocks.

Panel A of Table 3 reports the post-ranking liquidity betas of the decile portfolios when the stocks within each portfolio are value weighted. (The results for equally weighted portfolios, not shown, are nearly identical.) The liquidity betas are estimated by running the regression in (8) over the whole sample period, January 1966 through December 1999, as well as over two subperiods. The post-ranking liquidity betas increase across deciles, consistent with the objective of the sorting procedure. The "10-1" spread, which goes long decile 10 (stocks with high liquidity betas) and short decile 1 (stocks with low liquidity betas), has an overall-period liquidity beta of 8.23 , with a t-statistic of 2.37 .

Panel B of Table 3 reports some additional properties of portfolios sorted by predicted liquidity betas. The low-beta portfolios contain stocks of somewhat smaller firms: the average size in portfolio 1 is $\$ 257$ million, as compared to $\$ 1.3$ billion in portfolio ten (averaged over time). Stocks in the low-beta portfolios also tend to be less liquid, as measured by the average value of $\hat{\gamma}_{i t}$. Panel $\mathrm{B}$ also reports the decile portfolios' betas with respect to the Fama-French factors, MKT, SMB, and HML, and the previously described momentum factor, MOM. The Fama-French and momentum betas are estimated by regressing the decile excess returns on the returns of the four factor portfolios. All three Fama-French betas of the 10-1 spread are significantly negative: -0.30 for MKT, -0.65 for SMB, and -0.40 for HML. The SMB betas confirm the pattern in average capitalizations, and the HML betas indicate that the 10-1 spread has a tilt toward growth stocks. The 10-1 spread's momentum beta is significantly positive (0.11), suggesting some tilt toward past winners.

\subsubsection{Alphas}

If our liquidity risk factor is priced, we should see systematic differences in the average returns of our beta-sorted portfolios. The evidence in Table 4 indeed favors the pricing of liquidity risk. The table reports the value-weighted portfolios' post-ranking alphas estimated under three different factor specifications. The CAPM alpha is computed with respect to MKT, the Fama-French alpha with respect to the Fama-French factors, and the 4-factor alpha with respect to the Fama-French factors and MOM. All three alphas of the 10-1 spread are significantly positive: the CAPM alpha is $6.40 \%$ per year $(t=2.54)$, the Fama-French alpha is $9.23 \%$ per year $(t=4.29)$, and the 4 -factor alpha is $7.48 \%$ per year $(t=3.42)$. (Annual alphas are computed as 12 times the monthly estimates.) The alphas are also robust across 
the subperiods. For example, the subperiod Fama-French alphas of the 10-1 spread are 8.50\% $(t=2.77)$ and $10.74 \%(t=3.53)$, and the subperiod 4 -factor alphas are $6.21 \%(t=1.95)$ and $9.49 \%(t=3.12)$. Table 5 reports alphas when the decile portfolios are equally weighted rather than value weighted. These results are even slightly stronger. For example, the fullperiod CAPM, Fama-French, and 4-factor alphas of the equally weighted 10-1 spread are $8.23 \%, 10.49 \%$, and $7.66 \%$, respectively. The subperiod results are comparably strong, too.

We also test the hypothesis that all ten alphas are jointly equal to zero, using the test of Gibbons, Ross, and Shanken (1989). For both equally weighted and value-weighted portfolios and for all three models, the hypothesis is rejected at a $1 \%$ significance level in the overall period. The hypothesis is also rejected at the $5 \%$ level in both subperiods, for both equally weighted and value weighted portfolios and for all three models. The only exception occurs with the four-factor alphas for the value-weighted portfolios in the second subperiod, in which case the hypothesis is rejected at the $10 \%$ level.

Overall, the evidence strongly supports the hypothesis that our liquidity risk factor is priced. The premium for this risk is positive, in that stocks with higher sensitivity to aggregate liquidity shocks offer higher expected returns. The latter result is consistent with the notion that a pervasive drop in liquidity is seen as undesirable by the representative investor, so that investor requires compensation for holding stocks with greater exposure to this risk.

\subsubsection{Estimating the Premium Using All Ten Portfolios}

The discussion above relies on the 10-1 spread to infer that the expected-return premium associated with liquidity risk is positive. We can also estimate the liquidity risk premium using all ten decile portfolios. Define the multivariate regression,

$$
r_{t}=\beta_{0}+B \mathrm{~F}_{t}+\beta^{\mathcal{L}} \mathcal{L}_{t}+e_{t},
$$

where $r_{t}$ is a $10 \times 1$ vector containing the excess returns on the decile portfolios, and $\mathrm{F}_{t}$ is a $4 \times 1$ vector containing the realizations of the "traded" factors MKT, SMB, HML, and MOM, $B$ is a $10 \times 4$ matrix, and $\beta_{0}$ and $\beta^{\mathcal{L}}$ are $10 \times 1$ vectors. We also consider a specification

with only three traded factors, excluding MOM. Assume the decile portfolios are priced by the returns' sensitivities to the traded factors and the non-traded liquidity factor:

$$
\mathrm{E}\left(r_{t}\right)=B \lambda_{\mathrm{F}}+\beta^{\mathcal{L}} \lambda_{\mathcal{L}},
$$


where $\mathrm{E}(\cdot)$ denotes the unconditional expectation. Taking expectations of both sides of equation (13) and substituting from equation (14) gives

$$
\beta_{0}=\beta^{\mathcal{L}}\left[\lambda_{\mathcal{L}}-\mathrm{E}\left(\mathcal{L}_{t}\right)\right]
$$

since the vector of premia on the traded factors, $\lambda_{\mathrm{F}}$, is equal to $\mathrm{E}\left(\mathrm{F}_{t}\right)$. The liquidity factor $\mathcal{L}_{t}$ is not the payoff on a traded position, so in general the liquidity risk premium $\lambda_{\mathcal{L}}$ is not equal to $\mathrm{E}\left(\mathcal{L}_{t}\right)$. We estimate $\lambda_{\mathcal{L}}$ using the Generalized Method of Moments (GMM) of Hansen (1982). Let $\theta$ denote the set of unknown parameters: $\lambda_{\mathcal{L}}, \beta^{\mathcal{L}}, B$, and $\mathrm{E}\left(\mathcal{L}_{t}\right)$. The GMM estimator of $\theta$ minimizes $g(\theta)^{\prime} W g(\theta)$, where $g(\theta)=(1 / T) \sum_{t=1}^{T} f_{t}(\theta)$,

$$
\begin{gathered}
f_{t}(\theta)=\left(\begin{array}{c}
h_{t} \otimes e_{t} \\
\mathcal{L}_{t}-\mathrm{E}\left(\mathcal{L}_{t}\right)
\end{array}\right), \\
h_{t}^{\prime}=\left(\begin{array}{ccc}
1 & F_{t}^{\prime} & \mathcal{L}_{t}
\end{array}\right), \\
e_{t}=r_{t}-\beta^{\mathcal{L}}\left[\lambda_{\mathcal{L}}-\mathrm{E}\left(\mathcal{L}_{t}\right)\right]-B F_{t}-\beta^{\mathcal{L}} \mathcal{L}_{t},
\end{gathered}
$$

and $W$ is a consistent estimator of the optimal weighting matrix. ${ }^{16}$

Estimates of the liquidity risk premium $\lambda_{\mathcal{L}}$ are reported in Table 6, along with asymptotic t-statistics. Results are reported for both value-weighted and equally weighted portfolios. The full-period estimate of $\lambda_{\mathcal{L}}$ is significantly positive for both sets of portfolios under both specifications (three traded factors or four). The subperiod estimates are all positive, and the majority are statistically significant. Overall, estimating the liquidity risk premium using all ten portfolios confirms the previous inferences based on the extreme deciles. ${ }^{17}$ Again, liquidity risk appears to be an economically important determinant of expected stock returns.

The magnitude of the liquidity risk premium $\lambda_{\mathcal{L}}$ depends on the arbitrary scaling of $\mathcal{L}_{t}$ described earlier, but that scaling does not affect the t-statistic or the product $\beta_{i}^{\mathcal{L}} \lambda_{\mathcal{L}}$, the contribution of liquidity risk to asset $i$ 's expected return. Table 6 also reports the GMM estimates of $\left(\beta_{10}^{\mathcal{L}}-\beta_{1}^{\mathcal{L}}\right) \lambda_{\mathcal{L}}$, the difference between expected returns on the extreme decile portfolios implied by their liquidity betas. In the overall period, the annualized estimate of $\left(\beta_{10}^{\mathcal{L}}-\beta_{1}^{\mathcal{L}}\right) \lambda_{\mathcal{L}}$ is $9.63 \%$ with three traded factors and $7.56 \%$ with four (the corresponding values for equally weighted portfolios are $11.06 \%$ and $8.56 \%$ ). These values are close to the 10-1 spread alphas in Table 4 of $9.23 \%$ and $7.48 \%$ (the corresponding values in Table 5 for equally weighted portfolios are $10.49 \%$ and $7.66 \%$ ). Thus, even when the liquidity premium

\footnotetext{
${ }^{16}$ Following Hansen (1982), we estimate $W$ as the inverse of $(1 / T) \sum_{t=1}^{T} \hat{f}_{t} \hat{f}_{t}^{\prime}$, where $\hat{f}_{t}$ is equal to $f_{t}(\theta)$ evaluated at a consistent estimator of $\theta$, obtained by minimizing $g(\theta)^{\prime} g(\theta)$.

${ }^{17}$ In no case does the asymptotic chi-square test reject the restriction in (14) at standard significance levels.
} 
is estimated using all ten portfolios, the contribution of liquidity risk to the 10-1 expectedreturn difference remains virtually unchanged. The contributions of the traded factors to the expected return of the 10-1 spread are much smaller, all below $2 \%$ per year in absolute value for the overall period.

\section{2. $\quad$ Sorting by Historical Liquidity Betas}

As discussed earlier, a stock's historical liquidity beta is the most important predictor of its future liquidity beta (Table 2). If liquidity betas are sufficiently stable over time, sorting on the historical liquidity betas alone could produce dispersion in the post-ranking betas. This section shows that this is indeed the case, although the dispersion in the betas is not as large as when liquidity betas are predicted using additional variables. Although our study focuses primarily on the results produced by sorts on betas predicted with the larger set of variables, we present here some results based on historical-beta sorts in order to show that the results do not hinge on the inclusion of the additional variables.

At the end of each year between 1967 and 1998, we identify stocks with at least five years of monthly returns continuing through the current year-end. For each stock, we estimate its historical liquidity beta by running the regression in (8) using the most recent five years of monthly data. We impose a five-year minimum here in estimating the historical beta, as compared to the minimum of three years required to compute historical betas in the previous analysis. With no other information about liquidity beta brought to bear, it seems reasonable to require a somewhat more precise historical estimate. The series of innovations $\left(\mathcal{L}_{t}\right.$ 's) is again recomputed at the end of each year. Stocks are then sorted by these historical betas into ten value-weighted portfolios. Analogous to our sort on the predicted betas, we obtain a January 1968 through December 1999 series of monthly returns on each decile portfolio by linking across years the post-ranking returns during the next 12 months. On average, there are 217 stocks in each decile portfolio, and no portfolio ever contains fewer than 108 stocks.

Table 7 reports, in the same format as Table 3, the post-ranking liquidity betas as well as the average market capitalization, liquidity, and Fama-French and momentum betas of the decile portfolios. Note that, although the pattern in the post-ranking liquidity betas is not monotonic, sorting on historical betas achieves some success in spreading the post-ranking betas. The liquidity beta of the 10-1 spread is positive at $5.99(t=1.88)$, not as large as the corresponding value of $8.23(t=2.37)$ obtained by sorting on the predicted betas. The SMB beta of the 10-1 spread is significantly negative, as in Table 3 , but the low-beta portfolio no 
longer has the lowest market capitalization. Rather, smaller firms now occupy both extremes of the historical-beta sort. The latter result is consistent with smaller (and more volatile) stocks producing noisier historical liquidity betas. Also, average liquidity is now lower at both extremes, unlike the pattern in Table 3. Finally, the tilt toward growth stocks and past winners observed in Table 3 disappears when sorting on historical liquidity betas.

Table 8 reports the value-weighted decile portfolios' post-ranking alphas. The dispersion in the alphas is now smaller compared to the previous results, which is consistent with the smaller dispersion in the post-ranking liquidity betas. Nevertheless, all three alphas of the 10-1 spread are still significantly positive in the overall period: the CAPM alpha is $4.66 \%$ per year $(t=2.36)$, the Fama-French alpha is $4.15 \%$ per year $(t=2.08)$, and the 4 -factor alpha is $4.87 \%$ per year $(t=2.38) .{ }^{18}$ Moreover, the liquidity risk premium estimated from the universe of all ten portfolios, obtained by the same GMM procedure used to produce the values in Table 6 , is positive and significant at the $10 \%$ level. With three traded factors the estimated premium is 0.80 with a t-statistic of 1.77 , and with four traded factors it is 1.04 with a t-statistic of 1.76 . Note that the magnitude of the premium in either case is fairly close to its counterpart in Table 6 . In summary, the analysis based solely on historical betas supports the conclusion that stocks with greater sensitivity to innovations in aggregate liquidity offer higher expected returns.

\section{3. $\quad$ Sorting By Size}

Total market capitalization, or "size," is a common criterion for sorting stocks in empirical investment studies, and size sorts often produce dispersion in a number of other characteristics. Table 9 reports various properties of decile portfolios formed by sorting on size at the end of each year, where the breakpoints are based on all eligible NYSE, AMEX, and NASDAQ stocks. Not surprisingly, smaller stocks are less liquid, in that the average value of $\hat{\gamma}_{i t}$ increases monotonically across deciles. The liquidity betas of the two or three portfolios containing the smallest stocks are large and significantly positive, while the betas for the other deciles exhibit no discernible pattern and are not significantly different from zero. When the size sort is instead based on breakpoints for NYSE stocks only, so that each decile contains the same number of NYSE stocks but more AMEX and NASDAQ stocks are assigned to the lower deciles, then the pattern in liquidity betas is fairly flat across all ten

\footnotetext{
${ }^{18}$ When the decile portfolios are equally weighted, the post-ranking betas are less disperse than when the portfolios are value-weighted, and the alphas lose significance but are still positive. This is consistent with greater estimation error in historical liquidity betas for smaller stocks, which are typically more volatile.
} 
deciles. In other words, in a sort on size, the very smallest firms tend to be those with high liquidity betas. It seems plausible that small and illiquid stocks might be those whose values are most impacted by drops in market-wide liquidity, particularly if those drops prompt some investors concerned with the overall liquidity of their portfolios to "flee" such stocks and move to assets with greater liquidity. At the same time, though, size is not the sole determinant of liquidity betas. Recall from Table 3 that, when sorting by predicted liquidity betas, the high-beta portfolios actually have somewhat higher average market capitalizations than the low-beta portfolios.

Table 9 also reports the size-sorted portfolios' alphas computed with respect to the four factors used previously (the excess market return and size, value, and momentum spreads). Note that, for both the equally and value-weighted portfolios, the estimated alpha for the decile of smallest firms is over $3 \%$ annually, with a t-statistic of 2.3 . This $3 \%$ positive abnormal return can be compared to the portion of expected return attributable to liquidity risk, computed as the product of the portfolio's liquidity beta and the estimate of the liquidity risk premium $\lambda_{\mathcal{L}}$ reported earlier. If we take the premium estimated using the value-weighted beta-sorted portfolios, reported in Panel A in Table 6 (and the lower of the overall-period estimates $)$, that product is $3.7 \%(=4.73 \times 0.78)$ for the equally weighted lowest size decile and $4.1 \%(=5.26 \times 0.78)$ for the value-weighted version. In other words, the liquidity risk of the small-firm portfolio appears to be more than sufficient to explain its abnormal return with respect to the other four factors.

\section{An Investment Perspective}

The evidence presented in the previous section reveals that liquidity risk is related to expected-return differences that are not explained by stocks' sensitivities to MKT, SMB, HML, and MOM. An equivalent characterization of this evidence is that no combination of the latter four factors (and riskless cash) is mean-variance efficient with respect to the universe of common stocks. ${ }^{19}$ In particular, the large and significant alphas for the 10-1 spreads reported in Tables 4 and 5 imply that adding such positions to an opportunity set consisting of the other four factors increases the maximum Sharpe ratio.

In a linear pricing model in which expected returns are explained by betas with respect to

\footnotetext{
${ }^{19}$ The equivalence between multi-beta asset pricing and mean-variance efficiency of some combination of benchmark portfolios is well known. For an early recognition of this point see Merton (1973), and for later discussions see Jobson and Korkie (1982, 1985), Grinblatt and Titman (1987), and Huberman, Kandel, and Stambaugh (1987).
} 
non-traded factors, expected returns are also explained by betas with respect to portfolios whose returns are maximally correlated with those factors. ${ }^{20}$ Constructing a maximumcorrelation portfolio for $\mathcal{L}_{t}$ from the universe of common stocks is a challenging problem that lies beyond the scope of this study. It is the case that, if the ex post maximum correlation portfolio is constructed from the six-asset universe consisting of the first and last decile portfolios of the liquidity-beta sort as well as the four factors MKT, SMB, HML, and MOM, then the weight on the high-liquidity-beta portfolio is positive and the weight on the low-liquidity-beta portfolio is negative (for both the value-weighted and equally weighted versions of those portfolios). In this sense, adding the 10-1 spread to an investment universe consisting of the original four factors is motivated by a model in which expected returns are related to liquidity risk.

Let $\mathrm{LIQ}^{V}$ denote the payoff on the 10-1 spread constructed using value-weighted decile portfolios sorted on predicted liquidity betas, and let $\mathrm{LIQ}^{E}$ denote the payoff on the equally weighted version. To provide an additional perspective on the importance of liquidity risk, we examine here the degree to which the mean-variance opportunity set is enhanced by adding $\mathrm{LIQ}^{V}$ or $\mathrm{LIQ}^{E}$ to MKT, SMB, HML, and MOM. Of course, a mean-varianceefficient portfolio is not necessarily the optimal choice of an investor in a world that gives rise to multi-beta pricing, but we believe a mean-variance setting is of interest to many investors nevertheless. Panel A of Table 10 reports, for the overall 1966-1999 period, the maximum ex post Sharpe ratio and the weights in the corresponding tangency portfolio for various subsets of the six factors. For ease of discussion, let $S^{*}$ denote the maximum Sharpe ratio for a given set of assets. The original four factors have an $S^{*}$ of 0.33 (on a monthly basis). When $\mathrm{LIQ}^{V}$ is added, $S^{*}$ increases to 0.37 , and $\mathrm{LIQ}^{V}$ receives a greater weight in the ex post tangency portfolio than MOM (15.6\% versus $11.9 \%$ ). When $\mathrm{LIQ}^{E}$ is added to the original four, $S^{*}$ increases to 0.42 , and the weight in MOM drops by more than two-thirds, from $20.9 \%$ to $6.5 \%$. In contrast, the weight on $\mathrm{LIQ}^{E}$ in that case is $25.6 \%$, which is higher than the weights on all but HML (29.6\%). Moreover, we see that when adding a fourth factor to the three Fama-French factors, which by themselves have an $S^{*}$ of $0.22, \mathrm{LIQ}^{E}$ is more valuable than MOM by the mean-variance comparison: $\mathrm{LIQ}^{E}$ raises $S^{*}$ to 0.40 while MOM raises it to 0.33 .

Since $\mathrm{LIQ}^{V}$ and $\mathrm{LIQ}^{E}$ figure prominently in the ex-post tangency portfolio, at the expense of MOM especially, we are led to investigate a bit further the extent to which the momentum factor's importance is reduced by our liquidity-risk spreads. Panel B of Table 10 reports

\footnotetext{
${ }^{20}$ Huberman, Kandel, and Stambaugh (1987) characterize the "mimicking" portfolios that can be used in place of non-traded factors when betas with respect to the latter explain expected returns.
} 
the alpha for MOM when regressed on the three Fama-French factors plus either $\mathrm{LIQ}^{V}$ or $\mathrm{LIQ}^{E}$. In the overall period, momentum's annualized alpha with respect to just the three Fama-French factors is $16.3 \%$ with a t-statistic of 4.85 , confirming a well-known result. Adding $\mathrm{LIQ}^{V}$ reduces momentum's alpha somewhat, to $13.9 \%$ with a t-statistic of 4.09 . The momentum factor MOM is a spread between equally weighted portfolios, and perhaps for that reason the effect on its alpha of adding $\mathrm{LIQ}^{E}$ to the Fama-French factors is more dramatic. That equally weighted liquidity-risk spread cuts momentum's overall-period alpha nearly in half, to $8.4 \%$ with a t-statistic of 2.55. In the more recent 17-year subperiod from 1983 through 1999, momentum's estimated alpha in the presence of $\mathrm{LIQ}^{E}$ is actually negative, at -1.29 .

Although such evidence is tantalizing, it is difficult to conclude that liquidity risk provides a partial explanation for momentum. The liquidity beta of MOM, estimated as the coefficient on $\mathcal{L}_{t}$ in a multiple regression that includes the three Fama-French factors, is positive but not statistically significant at conventional levels in the overall period (6.9 with a t-statistic of 1.3). Moreover, in the later subperiod, when $\mathrm{LIQ}^{E}$ eliminates MOM's alpha, the estimated liquidity beta of MOM is negative (-1.65 with a t-statistic of -0.23). At the same time, though, we must remember that the non-traded factor $\mathcal{L}_{t}$ is at best an imperfect proxy for whatever correct measure of liquidity could be relevant for asset pricing. It remains possible that the 10-1 spread constructed by ranking on betas with respect to $\mathcal{L}_{t}$ comes closer to the correct mimicking portfolio than does $\mathcal{L}_{t}$ to the correct liquidity measure. At this point, however, we can simply observe that momentum's importance in an investment context is impacted significantly by the addition of spreads based on liquidity risk.

\section{Conclusions}

Market-wide liquidity appears to be a state variable that is important for pricing common stocks. We find that expected stock returns are related cross-sectionally to the sensitivities of stock returns to innovations in aggregate liquidity. Stocks that are more sensitive to aggregate liquidity have substantially higher expected returns, even after accounting for exposures to the market return as well as size, value, and momentum factors.

Our liquidity measure captures a dimension of liquidity associated with the strength of volume-related return reversals. Over the last four decades, this measure of market-wide liquidity exhibits a number of sharp declines, many of which coincide with market downturns and apparent flights to quality. Our liquidity measure is also characterized by significant 
commonality across stocks, supporting the notion of aggregate liquidity as a priced state variable. Smaller stocks are less liquid, according to our measure, and the smallest stocks have high sensitivities to aggregate liquidity.

One direction for future research is to explore whether liquidity risk plays a role in various pricing anomalies in financial markets. This study takes a step on this path by showing that the momentum strategy of buying recent winning stocks and selling recent losing stocks becomes less attractive from an investment perspective when portfolio spreads based on liquidity risk are also available for investment. Future research could also investigate whether expected returns are related to stocks' sensitivities to fluctuations in other aspects of aggregate liquidity, such as quoted and effective bid-ask spreads, market depth, trading volume, and turnover. In addition, it would be useful to explore whether some form of systematic liquidity risk is priced in other financial markets, such as fixed income markets or international equity markets. 


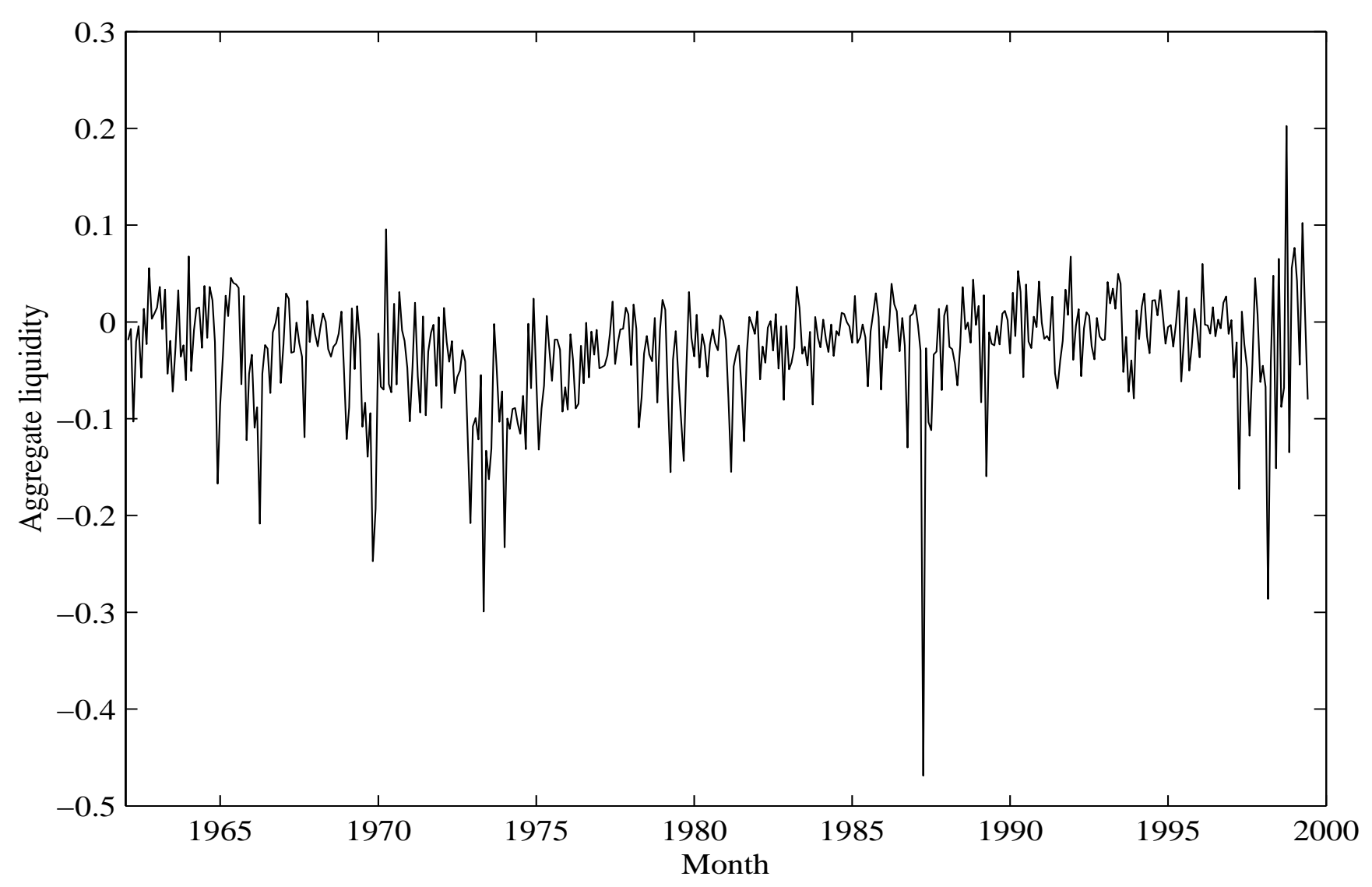

Figure 1. Aggregate liquidity. Each month's observation is constructed by averaging individual-stock measures for the month and then multiplying by $\left(m_{t} / m_{1}\right)$, where $m_{t}$ is the total dollar value at the end of month $t-1$ of the stocks included in the average in month $t$, and month 1 corresponds to August 1962. An individual stock's measure for a given month is a regression slope coefficient estimated using daily returns and volume data within that month. Tick marks correspond to July of the given year. 


\section{Table 1}

\section{Correlations of Monthly Stock Market Returns with Other Variables in Months with Large Liquidity Drops}

The table reports the correlation between the monthly return on the CRSP value-weighted NYSE-AMEX index, $R_{S, t}$, and (i) minus the change in the rate on one-month Treasury bills, $-\Delta R_{f, t}$, (ii) the return on long-term government bonds, $R_{G B, t}$, (iii) the return on long-term corporate bonds, $R_{C B, t}$, and (iv) the

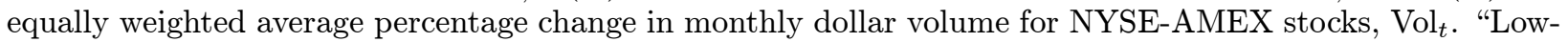
liquidity" months are those in which the innovation in the liquidity series is at least two standard deviations below zero. The p-values for the hypothesis that the correlations during these months are equal to those in other months are computed by a bootstrap approach.

\begin{tabular}{|c|c|c|c|c|c|}
\hline & \multicolumn{4}{|c|}{ Correlation of $R_{S, t}$ with } & \multirow{2}{*}{$\begin{array}{l}\text { Number of } \\
\text { observations }\end{array}$} \\
\hline & $-\Delta R_{f, t}$ & $R_{G B, t}$ & $R_{C B, t}$ & $\mathrm{Vol}_{t}$ & \\
\hline \multicolumn{6}{|c|}{ Jan 1962 - Dec 1999} \\
\hline All months & 0.047 & 0.323 & 0.372 & 0.491 & 449 \\
\hline Low-liquidity months (by 2 std. dev.'s) & -0.387 & -0.197 & -0.278 & -0.360 & 14 \\
\hline Other months & 0.092 & 0.362 & 0.406 & 0.522 & 435 \\
\hline $\mathrm{P}$-value & 0.087 & 0.045 & 0.018 & 0.002 & \\
\hline \multicolumn{6}{|c|}{ Aug 1962 - Mar 1981} \\
\hline All months & 0.077 & 0.285 & 0.376 & 0.567 & 224 \\
\hline Low-liquidity months (by 2 std. dev.'s) & -0.194 & 0.247 & -0.370 & -0.362 & 7 \\
\hline Other months & 0.079 & 0.285 & 0.378 & 0.572 & 217 \\
\hline $\mathrm{P}$-value & 0.279 & 0.426 & 0.070 & 0.016 & \\
\hline \multicolumn{6}{|c|}{ April 1981 - Dec 1999} \\
\hline All months & 0.007 & 0.353 & 0.365 & 0.394 & 225 \\
\hline Low-liquidity months (by 2 std. dev.'s) & -0.573 & -0.401 & -0.307 & -0.306 & 8 \\
\hline Other months & 0.105 & 0.433 & 0.434 & 0.459 & 217 \\
\hline $\mathrm{P}$-value & 0.048 & 0.033 & 0.040 & 0.038 & \\
\hline
\end{tabular}




\section{Table 2}

\section{Determinants of Predicted Liquidity Betas}

Each column reports the results of estimating a linear relation between a stock's liquidity beta and the seven characteristics listed (in addition to the intercept, shown first). At each year-end shown, the estimation uses all stocks defined as ordinary common shares traded on the NYSE, AMEX, or NASDAQ with at least three years of monthly returns continuing through the given year-end. The estimation uses a two-stage pooled time-series and cross-sectional approach. Each value reported is equal to the coefficient estimate multiplied by the time-series average of the annual cross-sectional standard deviations of the characteristic. The $t$-statistics are in parentheses.

\begin{tabular}{|c|c|c|c|}
\hline & \multicolumn{3}{|c|}{ Aug 1962 through } \\
\hline & Dec 1998 & Dec 1983 & Dec 1968 \\
\hline Intercept & $\begin{array}{l}-1.79 \\
(-6.75)\end{array}$ & $\begin{array}{c}-4.39 \\
(-12.94)\end{array}$ & $\begin{array}{l}-2.75 \\
(-2.95)\end{array}$ \\
\hline Historical beta & $\begin{array}{c}2.30 \\
(9.97)\end{array}$ & $\begin{array}{c}3.75 \\
(10.87)\end{array}$ & $\begin{array}{c}9.18 \\
(9.99)\end{array}$ \\
\hline Average liquidity & $\begin{array}{l}-0.87 \\
(-4.12)\end{array}$ & $\begin{array}{l}-0.02 \\
(-0.08)\end{array}$ & $\begin{array}{l}-0.48 \\
(-0.61)\end{array}$ \\
\hline Average volume & $\begin{array}{c}1.54 \\
(3.29)\end{array}$ & $\begin{array}{c}-3.37 \\
(-5.03)\end{array}$ & $\begin{array}{c}0.07 \\
(0.05)\end{array}$ \\
\hline Cumulative return & $\begin{array}{c}-0.04 \\
(-0.14)\end{array}$ & $\begin{array}{c}1.00 \\
(2.86)\end{array}$ & $\begin{array}{c}0.93 \\
(0.86)\end{array}$ \\
\hline Return volatility & $\begin{array}{c}-0.24 \\
(-1.60)\end{array}$ & $\begin{array}{l}-1.13 \\
(-3.39)\end{array}$ & $\begin{array}{l}-2.61 \\
(-2.25)\end{array}$ \\
\hline Price & $\begin{array}{c}0.59 \\
(1.85)\end{array}$ & $\begin{array}{c}7.51 \\
(15.00)\end{array}$ & $\begin{array}{c}4.32 \\
(3.38)\end{array}$ \\
\hline Shares outstanding & $\begin{array}{l}-1.43 \\
(-3.37)\end{array}$ & $\begin{array}{c}0.67 \\
(1.26)\end{array}$ & $\begin{array}{l}-0.69 \\
(-0.54)\end{array}$ \\
\hline
\end{tabular}




\section{Table 3}

\section{Properties of Portfolios Sorted on Predicted Liquidity Betas}

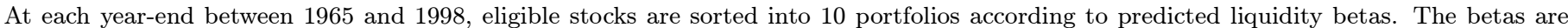

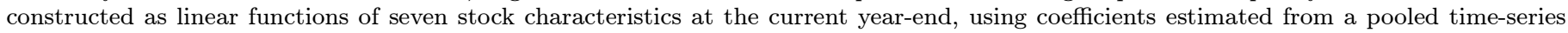

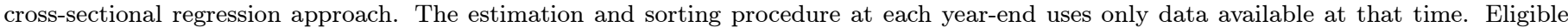

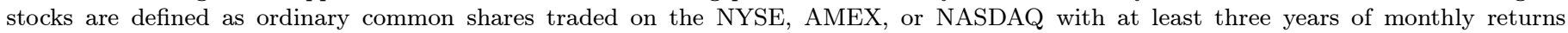

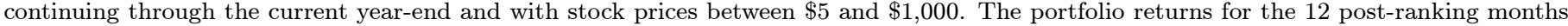

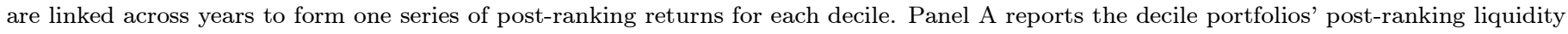

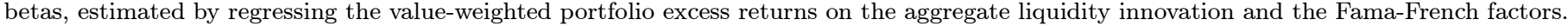

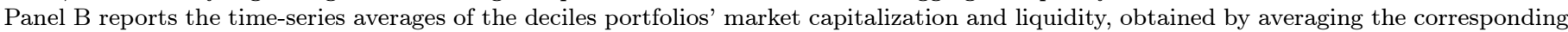

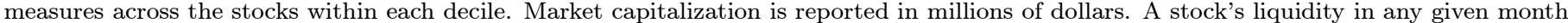

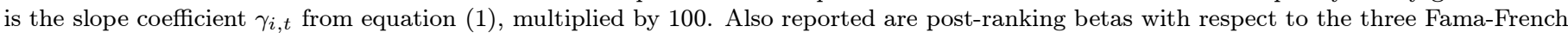

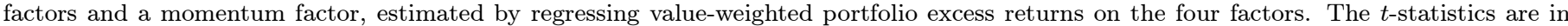
parentheses.

\begin{tabular}{|c|c|c|c|c|c|c|c|c|c|c|c|}
\hline & 1 & 2 & 3 & 4 & 5 & 6 & 7 & 8 & 9 & 10 & $10-1$ \\
\hline \multicolumn{12}{|c|}{ Panel A. Post-ranking liquidity betas } \\
\hline Jan 1966-Dec 1999 & $\begin{array}{c}-5.75 \\
(-2.22)\end{array}$ & $\begin{array}{c}-6.54 \\
(-2.98)\end{array}$ & $\begin{array}{c}-4.66 \\
(-2.59)\end{array}$ & $\begin{array}{c}-3.16 \\
(-2.18)\end{array}$ & $\begin{array}{c}0.90 \\
(0.69)\end{array}$ & $\begin{array}{c}-0.63 \\
(-0.54)\end{array}$ & $\begin{array}{c}-0.86 \\
(-0.68)\end{array}$ & $\begin{array}{c}0.68 \\
(0.52)\end{array}$ & $\begin{array}{c}2.44 \\
(1.77)\end{array}$ & $\begin{array}{c}2.48 \\
(1.35)\end{array}$ & $\begin{array}{c}8.23 \\
(2.37)\end{array}$ \\
\hline Jan 1966-Dec 1982 & $\begin{array}{c}-7.28 \\
(-1.84)\end{array}$ & $\begin{array}{c}-8.29 \\
(-2.54)\end{array}$ & $\begin{array}{c}-3.47 \\
(-1.19)\end{array}$ & $\begin{array}{c}-3.15 \\
(-1.36)\end{array}$ & $\begin{array}{c}2.58 \\
(1.23)\end{array}$ & $\begin{array}{c}-0.34 \\
(-0.17)\end{array}$ & $\begin{array}{c}-0.47 \\
(-0.22)\end{array}$ & $\begin{array}{c}0.73 \\
(0.33)\end{array}$ & $\begin{array}{c}-2.51 \\
(-1.10)\end{array}$ & $\begin{array}{c}4.19 \\
(1.38)\end{array}$ & $\begin{array}{l}11.47 \\
(2.06)\end{array}$ \\
\hline Jan 1983-Dec 1999 & $\begin{array}{l}-3.00 \\
(-0.85)\end{array}$ & $\begin{array}{c}-4.27 \\
(-1.37)\end{array}$ & $\begin{array}{c}-5.09 \\
(-2.12)\end{array}$ & $\begin{array}{c}-2.36 \\
(-1.22)\end{array}$ & $\begin{array}{l}-1.10 \\
(-0.63)\end{array}$ & $\begin{array}{c}-0.84 \\
(-0.57)\end{array}$ & $\begin{array}{c}-1.60 \\
(-1.06)\end{array}$ & $\begin{array}{c}1.94 \\
(1.22)\end{array}$ & $\begin{array}{c}5.67 \\
(3.23)\end{array}$ & $\begin{array}{c}0.85 \\
(0.36)\end{array}$ & $\begin{array}{c}3.85 \\
(0.84)\end{array}$ \\
\hline \multicolumn{12}{|c|}{ Panel B. Additional properties, Jan 1966 - Dec 1999} \\
\hline Market cap & 257.27 & 494.52 & 728.36 & 937.26 & 1173.87 & 1450.99 & 1418.38 & 1518.23 & 1473.44 & 1296.18 & \\
\hline Liquidity & -1.44 & -0.99 & -0.82 & -0.83 & -0.51 & -0.51 & -0.48 & -0.34 & -0.38 & -0.46 & \\
\hline MKT beta & $\begin{array}{c}1.24 \\
(37.70)\end{array}$ & $\begin{array}{c}1.21 \\
(44.61)\end{array}$ & $\begin{array}{c}1.09 \\
(48.31)\end{array}$ & $\begin{array}{c}1.05 \\
(56.83)\end{array}$ & $\begin{array}{c}1.04 \\
(62.83)\end{array}$ & $\begin{array}{c}1.03 \\
(68.89)\end{array}$ & $\begin{array}{c}1.00 \\
(62.56)\end{array}$ & $\begin{array}{c}1.01 \\
(60.75)\end{array}$ & $\begin{array}{c}0.98 \\
(55.76)\end{array}$ & $\begin{array}{c}0.94 \\
(40.75)\end{array}$ & $\begin{array}{c}-0.30 \\
(-6.85)\end{array}$ \\
\hline SMB beta & $\begin{array}{c}0.70 \\
(14.47)\end{array}$ & $\begin{array}{c}0.31 \\
(7.64)\end{array}$ & $\begin{array}{c}0.05 \\
(1.61)\end{array}$ & $\begin{array}{c}0.01 \\
(0.26)\end{array}$ & $\begin{array}{c}-0.09 \\
(-3.51)\end{array}$ & $\begin{array}{c}-0.12 \\
(-5.63)\end{array}$ & $\begin{array}{c}-0.12 \\
(-5.04)\end{array}$ & $\begin{array}{c}-0.09 \\
(-3.82)\end{array}$ & $\begin{array}{c}-0.12 \\
(-4.76)\end{array}$ & $\begin{array}{c}0.05 \\
(1.36)\end{array}$ & $\begin{array}{c}-0.65 \\
(-10.14)\end{array}$ \\
\hline HML beta & $\begin{array}{c}0.07 \\
(1.31)\end{array}$ & $\begin{array}{c}0.19 \\
(4.36)\end{array}$ & $\begin{array}{c}0.23 \\
(6.45)\end{array}$ & $\begin{array}{c}0.20 \\
(6.69)\end{array}$ & $\begin{array}{c}0.11 \\
(4.02)\end{array}$ & $\begin{array}{c}0.14 \\
(5.68)\end{array}$ & $\begin{array}{c}0.08 \\
(3.07)\end{array}$ & $\begin{array}{c}-0.00 \\
(-0.06)\end{array}$ & $\begin{array}{c}-0.01 \\
(-0.37)\end{array}$ & $\begin{array}{c}-0.34 \\
(-9.04)\end{array}$ & $\begin{array}{c}-0.40 \\
(-5.74)\end{array}$ \\
\hline MOM beta & $\begin{array}{c}-0.06 \\
(-2.43)\end{array}$ & $\begin{array}{c}-0.10 \\
(-5.35)\end{array}$ & $\begin{array}{c}-0.07 \\
(-4.29)\end{array}$ & $\begin{array}{c}-0.03 \\
(-2.19)\end{array}$ & $\begin{array}{c}-0.03 \\
(-2.51)\end{array}$ & $\begin{array}{c}-0.01 \\
(-0.72)\end{array}$ & $\begin{array}{c}0.01 \\
(0.53)\end{array}$ & $\begin{array}{c}-0.01 \\
(-0.72)\end{array}$ & $\begin{array}{c}0.03 \\
(2.72) \\
\end{array}$ & $\begin{array}{c}0.05 \\
(3.02) \\
\end{array}$ & $\begin{array}{c}0.11 \\
(3.41) \\
\end{array}$ \\
\hline
\end{tabular}




\section{Table 4}

\section{Alphas of Value-Weighted Portfolios Sorted on Predicted Liquidity Betas}

At each year-end between 1965 and 1998, eligible stocks are sorted into 10 portfolios according to predicted liquidity betas. The betas are constructed as linear functions of seven stock characteristics at the current year-end, using coefficients estimated from a pooled timeseries cross-sectional regression approach. The estimation and sorting procedure at each year-end uses only data available at that time. Eligible stocks are defined as ordinary common shares traded on the NYSE, AMEX, or NASDAQ with at least three years of monthly returns continuing through the current year-end and with stock prices between $\$ 5$ and $\$ 1,000$. The portfolio returns for the 12 postranking months are linked across years to form one series of post-ranking returns for each decile. The table reports the decile portfolios' post-ranking alphas, in percent per year. The alphas are estimated as intercepts from the regressions of excess portfolio post-ranking returns on excess market returns (CAPM alpha), on the Fama-French factor returns (Fama-French alpha), and on the Fama-French and momentum factor returns (4-factor alphas). The $t$-statistics are in parentheses.

\begin{tabular}{|c|c|c|c|c|c|c|c|c|c|c|c|}
\hline & 1 & 2 & 3 & 4 & 5 & 6 & 7 & 8 & 9 & 10 & $10-1$ \\
\hline \multicolumn{12}{|c|}{ Jan 1966 - Dec 1999} \\
\hline CAPM alpha & $\begin{array}{l}-5.16 \\
(-2.57)\end{array}$ & $\begin{array}{l}-1.88 \\
(-1.24)\end{array}$ & $\begin{array}{c}-0.66 \\
(-0.56)\end{array}$ & $\begin{array}{c}-0.07 \\
(-0.08)\end{array}$ & $\begin{array}{l}-1.48 \\
(-1.80)\end{array}$ & $\begin{array}{c}1.48 \\
(1.93)\end{array}$ & $\begin{array}{c}1.22 \\
(1.52)\end{array}$ & $\begin{array}{c}1.38 \\
(1.72)\end{array}$ & $\begin{array}{c}1.68 \\
(1.93)\end{array}$ & $\begin{array}{c}1.24 \\
(1.01)\end{array}$ & $\begin{array}{c}6.40 \\
(2.54)\end{array}$ \\
\hline Fama-French alpha & $\begin{array}{c}-6.05 \\
(-3.77)\end{array}$ & $\begin{array}{l}-3.36 \\
(-2.47)\end{array}$ & $\begin{array}{c}-2.15 \\
(-1.93)\end{array}$ & $\begin{array}{l}-1.23 \\
(-1.37)\end{array}$ & $\begin{array}{l}-2.10 \\
(-2.61)\end{array}$ & $\begin{array}{c}0.78 \\
(1.08)\end{array}$ & $\begin{array}{c}0.86 \\
(1.11)\end{array}$ & $\begin{array}{c}1.41 \\
(1.76)\end{array}$ & $\begin{array}{c}1.90 \\
(2.22)\end{array}$ & $\begin{array}{c}3.18 \\
(2.82)\end{array}$ & $\begin{array}{c}9.23 \\
(4.29)\end{array}$ \\
\hline 4-factor alpha & $\begin{array}{c}-5.11 \\
(-3.12)\end{array}$ & $\begin{array}{l}-1.66 \\
(-1.23)\end{array}$ & $\begin{array}{c}-1.02 \\
(-0.91)\end{array}$ & $\begin{array}{c}-0.76 \\
(-0.83)\end{array}$ & $\begin{array}{l}-1.61 \\
(-1.96)\end{array}$ & $\begin{array}{c}0.91 \\
(1.22)\end{array}$ & $\begin{array}{c}0.76 \\
(0.96)\end{array}$ & $\begin{array}{c}1.55 \\
(1.88)\end{array}$ & $\begin{array}{c}1.34 \\
(1.54)\end{array}$ & $\begin{array}{c}2.36 \\
(2.06)\end{array}$ & $\begin{array}{c}7.48 \\
(3.42)\end{array}$ \\
\hline \multicolumn{12}{|c|}{ Jan 1966 - Dec 1982} \\
\hline CAPM alpha & $\begin{array}{l}-2.26 \\
(-0.81)\end{array}$ & $\begin{array}{c}1.63 \\
(0.76)\end{array}$ & $\begin{array}{c}0.54 \\
(0.31)\end{array}$ & $\begin{array}{c}0.67 \\
(0.50)\end{array}$ & $\begin{array}{l}-3.09 \\
(-2.69)\end{array}$ & $\begin{array}{c}1.44 \\
(1.29)\end{array}$ & $\begin{array}{c}0.61 \\
(0.54)\end{array}$ & $\begin{array}{c}1.78 \\
(1.46)\end{array}$ & $\begin{array}{c}1.43 \\
(1.14)\end{array}$ & $\begin{array}{l}-0.93 \\
(-0.52)\end{array}$ & $\begin{array}{c}1.34 \\
(0.36)\end{array}$ \\
\hline Fama-French alpha & $\begin{array}{c}-7.32 \\
(-3.36)\end{array}$ & $\begin{array}{l}-2.22 \\
(-1.23)\end{array}$ & $\begin{array}{c}-1.80 \\
(-1.13)\end{array}$ & $\begin{array}{c}-0.75 \\
(-0.59)\end{array}$ & $\begin{array}{l}-3.29 \\
(-2.85)\end{array}$ & $\begin{array}{c}1.03 \\
(0.95)\end{array}$ & $\begin{array}{c}0.20 \\
(0.17)\end{array}$ & $\begin{array}{c}1.91 \\
(1.56)\end{array}$ & $\begin{array}{c}2.32 \\
(1.86)\end{array}$ & $\begin{array}{c}1.18 \\
(0.71)\end{array}$ & $\begin{array}{c}8.50 \\
(2.77)\end{array}$ \\
\hline 4-factor alpha & $\begin{array}{c}-6.43 \\
(-2.82)\end{array}$ & $\begin{array}{l}-0.25 \\
(-0.13)\end{array}$ & $\begin{array}{c}-0.22 \\
(-0.13)\end{array}$ & $\begin{array}{c}-0.03 \\
(-0.02)\end{array}$ & $\begin{array}{l}-2.46 \\
(-2.05)\end{array}$ & $\begin{array}{c}1.09 \\
(0.95)\end{array}$ & $\begin{array}{c}0.31 \\
(0.25)\end{array}$ & $\begin{array}{c}2.89 \\
(2.28)\end{array}$ & $\begin{array}{c}1.67 \\
(1.28)\end{array}$ & $\begin{array}{c}-0.22 \\
(-0.13)\end{array}$ & $\begin{array}{c}6.21 \\
(1.95)\end{array}$ \\
\hline \multicolumn{12}{|c|}{ Jan 1983 - Dec 1999} \\
\hline CAPM alpha & $\begin{array}{c}-8.01 \\
(-2.76)\end{array}$ & $\begin{array}{l}-5.33 \\
(-2.49)\end{array}$ & $\begin{array}{c}-1.76 \\
(-1.08)\end{array}$ & $\begin{array}{l}-1.01 \\
(-0.77)\end{array}$ & $\begin{array}{c}0.20 \\
(0.17)\end{array}$ & $\begin{array}{c}1.55 \\
(1.46)\end{array}$ & $\begin{array}{c}1.74 \\
(1.54)\end{array}$ & $\begin{array}{c}0.70 \\
(0.67)\end{array}$ & $\begin{array}{c}1.81 \\
(1.47)\end{array}$ & $\begin{array}{c}3.38 \\
(1.98)\end{array}$ & $\begin{array}{l}11.39 \\
(3.36)\end{array}$ \\
\hline Fama-French alpha & $\begin{array}{l}-5.23 \\
(-2.23)\end{array}$ & $\begin{array}{l}-5.08 \\
(-2.46)\end{array}$ & $\begin{array}{c}-2.69 \\
(-1.67)\end{array}$ & $\begin{array}{l}-1.80 \\
(-1.41)\end{array}$ & $\begin{array}{c}-0.82 \\
(-0.72)\end{array}$ & $\begin{array}{c}0.37 \\
(0.38)\end{array}$ & $\begin{array}{c}0.89 \\
(0.89)\end{array}$ & $\begin{array}{c}0.76 \\
(0.72)\end{array}$ & $\begin{array}{c}1.25 \\
(1.05)\end{array}$ & $\begin{array}{c}5.51 \\
(3.51)\end{array}$ & $\begin{array}{l}10.74 \\
(3.53)\end{array}$ \\
\hline 4-factor alpha & $\begin{array}{c}-4.43 \\
(-1.88)\end{array}$ & $\begin{array}{l}-3.72 \\
(-1.85)\end{array}$ & $\begin{array}{c}-1.94 \\
(-1.21)\end{array}$ & $\begin{array}{l}-1.52 \\
(-1.17)\end{array}$ & $\begin{array}{c}-0.63 \\
(-0.54)\end{array}$ & $\begin{array}{c}0.53 \\
(0.54)\end{array}$ & $\begin{array}{c}0.70 \\
(0.69)\end{array}$ & $\begin{array}{c}0.47 \\
(0.44)\end{array}$ & $\begin{array}{c}0.84 \\
(0.70)\end{array}$ & $\begin{array}{c}5.06 \\
(3.20)\end{array}$ & $\begin{array}{c}9.49 \\
(3.12)\end{array}$ \\
\hline
\end{tabular}




\section{Table 5}

\section{Alphas of Equally-Weighted Portfolios Sorted on Predicted Liquidity Betas}

At each year-end between 1965 and 1998, eligible stocks are sorted into 10 portfolios according to predicted liquidity betas. The betas are constructed as linear functions of seven stock characteristics at the current year-end, using coefficients estimated from a pooled timeseries cross-sectional regression approach. The estimation and sorting procedure at each year-end uses only data available at that time. Eligible stocks are defined as ordinary common shares traded on the NYSE, AMEX, or NASDAQ with at least three years of monthly returns continuing through the current year-end and with stock prices between $\$ 5$ and $\$ 1,000$. The portfolio returns for the 12 postranking months are linked across years to form one series of post-ranking returns for each decile. The table reports the decile portfolios' post-ranking alphas, in percent per year. The alphas are estimated as intercepts from the regressions of excess portfolio post-ranking returns on excess market returns (CAPM alpha), on the Fama-French factor returns (Fama-French alpha), and on the Fama-French and momentum factor returns (4-factor alphas). The $t$-statistics are in parentheses.

\begin{tabular}{|c|c|c|c|c|c|c|c|c|c|c|c|}
\hline & 1 & 2 & 3 & 4 & 5 & 6 & 7 & 8 & 9 & 10 & $10-1$ \\
\hline \multicolumn{12}{|c|}{ Jan 1966 - Dec 1999} \\
\hline CAPM alpha & $\begin{array}{l}-5.46 \\
(-2.27)\end{array}$ & $\begin{array}{l}-1.47 \\
(-0.75)\end{array}$ & $\begin{array}{c}-0.73 \\
(-0.46)\end{array}$ & $\begin{array}{c}0.34 \\
(0.24)\end{array}$ & $\begin{array}{c}0.02 \\
(0.02)\end{array}$ & $\begin{array}{c}0.94 \\
(0.84)\end{array}$ & $\begin{array}{c}1.97 \\
(1.91)\end{array}$ & $\begin{array}{c}2.78 \\
(2.71)\end{array}$ & $\begin{array}{c}2.43 \\
(2.37)\end{array}$ & $\begin{array}{c}2.77 \\
(2.06)\end{array}$ & $\begin{array}{c}8.23 \\
(4.12)\end{array}$ \\
\hline Fama-French alpha & $\begin{array}{l}-7.53 \\
(-6.35)\end{array}$ & $\begin{array}{l}-3.47 \\
(-3.39)\end{array}$ & $\begin{array}{l}-3.04 \\
(-3.63)\end{array}$ & $\begin{array}{l}-1.58 \\
(-2.13)\end{array}$ & $\begin{array}{l}-1.67 \\
(-2.47)\end{array}$ & $\begin{array}{c}-0.76 \\
(-1.21)\end{array}$ & $\begin{array}{c}0.46 \\
(0.78)\end{array}$ & $\begin{array}{c}1.49 \\
(2.50)\end{array}$ & $\begin{array}{c}1.46 \\
(2.18)\end{array}$ & $\begin{array}{c}2.96 \\
(3.14)\end{array}$ & $\begin{array}{l}10.49 \\
(6.50)\end{array}$ \\
\hline 4-factor alpha & $\begin{array}{c}-5.80 \\
(-4.98)\end{array}$ & $\begin{array}{c}-1.64 \\
(-1.68)\end{array}$ & $\begin{array}{l}-1.68 \\
(-2.07)\end{array}$ & $\begin{array}{c}-0.68 \\
(-0.92)\end{array}$ & $\begin{array}{c}-1.02 \\
(-1.50)\end{array}$ & $\begin{array}{c}-0.17 \\
(-0.26)\end{array}$ & $\begin{array}{c}0.16 \\
(0.26)\end{array}$ & $\begin{array}{c}1.32 \\
(2.16)\end{array}$ & $\begin{array}{c}0.95 \\
(1.40)\end{array}$ & $\begin{array}{c}1.86 \\
(1.98)\end{array}$ & $\begin{array}{c}7.66 \\
(4.95)\end{array}$ \\
\hline \multicolumn{12}{|c|}{ Jan 1966 - Dec 1982} \\
\hline CAPM alpha & $\begin{array}{c}1.74 \\
(0.49)\end{array}$ & $\begin{array}{c}5.52 \\
(1.90)\end{array}$ & $\begin{array}{c}5.22 \\
(2.22)\end{array}$ & $\begin{array}{c}4.49 \\
(2.25)\end{array}$ & $\begin{array}{c}2.99 \\
(1.70)\end{array}$ & $\begin{array}{c}4.15 \\
(2.49)\end{array}$ & $\begin{array}{c}4.76 \\
(3.15)\end{array}$ & $\begin{array}{c}6.00 \\
(4.10)\end{array}$ & $\begin{array}{c}4.11 \\
(2.77)\end{array}$ & $\begin{array}{c}4.68 \\
(2.54)\end{array}$ & $\begin{array}{c}2.95 \\
(0.98)\end{array}$ \\
\hline Fama-French alpha & $\begin{array}{l}-6.50 \\
(-4.02)\end{array}$ & $\begin{array}{l}-1.12 \\
(-0.76)\end{array}$ & $\begin{array}{l}-0.80 \\
(-0.69)\end{array}$ & $\begin{array}{c}-0.51 \\
(-0.52)\end{array}$ & $\begin{array}{l}-1.21 \\
(-1.25)\end{array}$ & $\begin{array}{c}0.02 \\
(0.02)\end{array}$ & $\begin{array}{c}1.12 \\
(1.32)\end{array}$ & $\begin{array}{c}2.70 \\
(3.17)\end{array}$ & $\begin{array}{c}1.23 \\
(1.22)\end{array}$ & $\begin{array}{c}2.76 \\
(1.95)\end{array}$ & $\begin{array}{c}9.25 \\
(4.19)\end{array}$ \\
\hline 4-factor alpha & $\begin{array}{c}-5.32 \\
(-3.16)\end{array}$ & $\begin{array}{c}1.00 \\
(0.67)\end{array}$ & $\begin{array}{c}1.28 \\
(1.14)\end{array}$ & $\begin{array}{c}0.80 \\
(0.81)\end{array}$ & $\begin{array}{c}0.20 \\
(0.20)\end{array}$ & $\begin{array}{c}0.93 \\
(1.00)\end{array}$ & $\begin{array}{c}0.85 \\
(0.96)\end{array}$ & $\begin{array}{c}2.79 \\
(3.12)\end{array}$ & $\begin{array}{c}0.84 \\
(0.79)\end{array}$ & $\begin{array}{c}1.18 \\
(0.81)\end{array}$ & $\begin{array}{c}6.49 \\
(2.91)\end{array}$ \\
\hline \multicolumn{12}{|c|}{ Jan 1983 - Dec 1999} \\
\hline CAPM alpha & $\begin{array}{l}-11.47 \\
(-3.70)\end{array}$ & $\begin{array}{l}-7.36 \\
(-2.94)\end{array}$ & $\begin{array}{c}-6.09 \\
(-2.92)\end{array}$ & $\begin{array}{c}-3.06 \\
(-1.63)\end{array}$ & $\begin{array}{l}-2.21 \\
(-1.41)\end{array}$ & $\begin{array}{c}-1.58 \\
(-1.10)\end{array}$ & $\begin{array}{c}0.06 \\
(0.04)\end{array}$ & $\begin{array}{c}0.29 \\
(0.21)\end{array}$ & $\begin{array}{c}1.77 \\
(1.34)\end{array}$ & $\begin{array}{c}1.78 \\
(0.92)\end{array}$ & $\begin{array}{l}13.25 \\
(5.13)\end{array}$ \\
\hline Fama-French alpha & $\begin{array}{c}-8.90 \\
(-5.02)\end{array}$ & $\begin{array}{c}-5.83 \\
(-4.07)\end{array}$ & $\begin{array}{l}-5.58 \\
(-4.62)\end{array}$ & $\begin{array}{c}-2.58 \\
(-2.26)\end{array}$ & $\begin{array}{c}-2.08 \\
(-2.16)\end{array}$ & $\begin{array}{c}-1.56 \\
(-1.70)\end{array}$ & $\begin{array}{c}0.13 \\
(0.15)\end{array}$ & $\begin{array}{c}0.54 \\
(0.64)\end{array}$ & $\begin{array}{c}2.37 \\
(2.72)\end{array}$ & $\begin{array}{c}4.12 \\
(3.33)\end{array}$ & $\begin{array}{l}13.02 \\
(5.50)\end{array}$ \\
\hline 4-factor alpha & $\begin{array}{c}-7.10 \\
(-4.40)\end{array}$ & $\begin{array}{l}-4.34 \\
(-3.35)\end{array}$ & $\begin{array}{l}-4.73 \\
(-4.05)\end{array}$ & $\begin{array}{l}-2.00 \\
(-1.77)\end{array}$ & $\begin{array}{c}-1.92 \\
(-1.97)\end{array}$ & $\begin{array}{l}-1.19 \\
(-1.30)\end{array}$ & $\begin{array}{l}-0.13 \\
(-0.15)\end{array}$ & $\begin{array}{c}0.29 \\
(0.34)\end{array}$ & $\begin{array}{c}1.87 \\
(2.18)\end{array}$ & $\begin{array}{c}3.42 \\
(2.80)\end{array}$ & $\begin{array}{l}10.51 \\
(4.94)\end{array}$ \\
\hline
\end{tabular}




\section{Table 6}

\section{Liquidity Risk Premium and its Contribution to Expected Return}

The table reports the estimates of the risk premium associated with the liquidity factor, as well as the contribution of liquidity risk to the expected return on the "10-1" spread. Stocks are sorted into 10 portfolios by their predicted liquidity betas at each year-end. The premium $\lambda_{\mathcal{L}}$ is estimated using post-ranking returns on all 10 portfolios. The decile portfolios are value-weighted in Panel A and equally weighted in Panel B. The premium is reported as a monthly value multiplied by 1200 , so that the product of the liquidity beta and the reported premium can be interpreted as annual percentage return. The 10-1 spread goes long decile 10 , with high liquidity beta $\beta_{10}^{\mathcal{L}}$, and short decile 1 , with low liquidity beta $\beta_{1}^{\mathcal{L}}$. The contribution of liquidity risk to the portfolio's expected return, $\left(\beta_{10}^{\mathcal{L}}-\beta_{1}^{\mathcal{L}}\right) \lambda_{\mathcal{L}}$, is also expressed in percent per year. The asymptotic $t$-statistics are in parentheses.

$$
\text { Jan } 1966 \text { - Dec } 1999 \text { Jan } 1966 \text { - Dec } 1982 \quad \text { Jan } 1983 \text { - Dec } 1999
$$

Panel A. Value-weighted portfolios sorted on predicted betas

Three traded factors
$\lambda_{\mathcal{L}}$
0.91
0.81
1.13$$
\left(\beta_{10}^{\mathcal{L}}-\beta_{1}^{\mathcal{L}}\right) \lambda_{\mathcal{L}}
$$

Four traded factors
$\lambda_{\mathcal{L}}$
0.78
0.23
0.82$$
\left(\beta_{10}^{\mathcal{L}}-\beta_{1}^{\mathcal{L}}\right) \lambda_{\mathcal{L}}
$$

Panel B. Equally weighted portfolios sorted on predicted betas Three traded factors
$\lambda_{\mathcal{L}}$
1.65
1.28
1.10

$$
\left(\beta_{10}^{\mathcal{L}}-\beta_{1}^{\mathcal{L}}\right) \lambda_{\mathcal{L}}
$$

Four traded factors

$\begin{array}{cccc}\lambda_{\mathcal{L}} & 1.72 & 3.01 & 1.02 \\ \left(\beta_{10}^{\mathcal{L}}-\beta_{1}^{\mathcal{L}}\right) \lambda_{\mathcal{L}} & (2.33) & (0.74) & (3.49) \\ & 8.56 & 8.20 & 10.14 \\ & (5.53) & (3.03) & (4.07)\end{array}$




\section{Table 7}

\section{Properties of Portfolios Sorted on Historical Liquidity Betas}

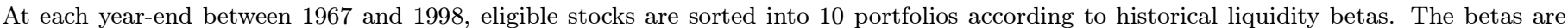

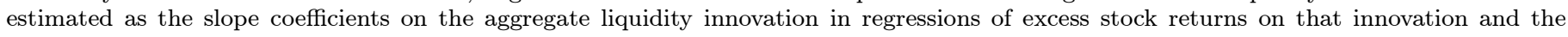

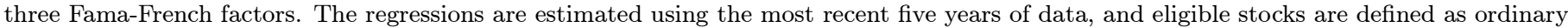

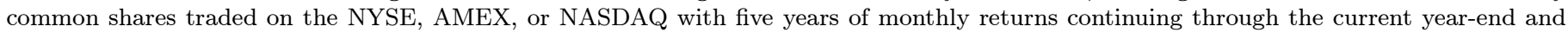

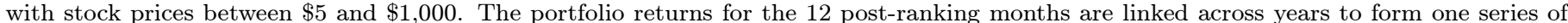

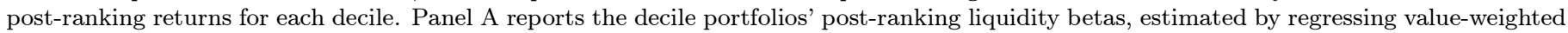

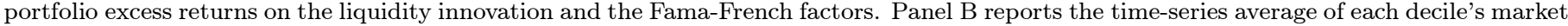

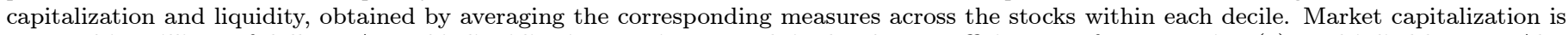

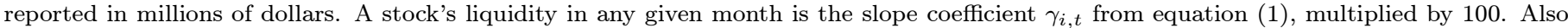

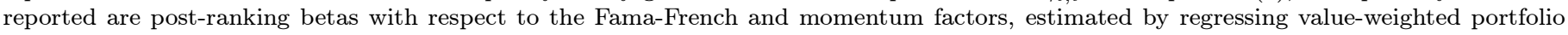
excess returns on the four factors. The $t$-statistics are in parentheses.

\begin{tabular}{|c|c|c|c|c|c|c|c|c|c|c|c|}
\hline & 1 & 2 & 3 & 4 & 5 & 6 & 7 & 8 & 9 & 10 & $10-1$ \\
\hline \multicolumn{12}{|c|}{ Panel A. Liquidity betas } \\
\hline Jan 1968 - Dec 1999 & $\begin{array}{l}-6.02 \\
(-2.57)\end{array}$ & $\begin{array}{l}-0.65 \\
(-0.37)\end{array}$ & $\begin{array}{c}-0.62 \\
(-0.48)\end{array}$ & $\begin{array}{c}-0.54 \\
(-0.41)\end{array}$ & $\begin{array}{c}1.12 \\
(0.96)\end{array}$ & $\begin{array}{l}-1.58 \\
(-1.24)\end{array}$ & $\begin{array}{c}1.37 \\
(1.00)\end{array}$ & $\begin{array}{l}2.00 \\
(1.49)\end{array}$ & $\begin{array}{c}3.04 \\
(1.99)\end{array}$ & $\begin{array}{l}-0.04 \\
(-0.02)\end{array}$ & $\begin{array}{c}5.99 \\
(1.88)\end{array}$ \\
\hline Jan 1968 - Dec 1983 & $\begin{array}{l}-7.59 \\
(-1.84)\end{array}$ & $\begin{array}{l}-1.17 \\
(-0.44)\end{array}$ & $\begin{array}{c}3.87 \\
(1.86)\end{array}$ & $\begin{array}{c}-1.54 \\
(-0.68)\end{array}$ & $\begin{array}{l}-0.48 \\
(-0.25)\end{array}$ & $\begin{array}{c}1.65 \\
(0.71)\end{array}$ & $\begin{array}{l}-1.18 \\
(-0.55)\end{array}$ & $\begin{array}{c}0.02 \\
(0.01)\end{array}$ & $\begin{array}{l}1.26 \\
(0.54)\end{array}$ & $\begin{array}{c}0.41 \\
(0.14)\end{array}$ & $\begin{array}{c}7.99 \\
(1.60)\end{array}$ \\
\hline Jan 1984 - Dec 1999 & $\begin{array}{l}-4.17 \\
(-1.52)\end{array}$ & $\begin{array}{l}-1.49 \\
(-0.63)\end{array}$ & $\begin{array}{l}-4.10 \\
(-2.46)\end{array}$ & $\begin{array}{c}-0.30 \\
(-0.18)\end{array}$ & $\begin{array}{c}2.55 \\
(1.72)\end{array}$ & $\begin{array}{l}-2.75 \\
(-2.00)\end{array}$ & $\begin{array}{c}2.80 \\
(1.56)\end{array}$ & $\begin{array}{c}3.79 \\
(2.08)\end{array}$ & $\begin{array}{c}4.38 \\
(2.07)\end{array}$ & $\begin{array}{c}1.18 \\
(0.39)\end{array}$ & $\begin{array}{c}5.35 \\
(1.26)\end{array}$ \\
\hline \multicolumn{12}{|c|}{ Panel B. Additional properties, Jan 1968 - Dec 1999} \\
\hline Market cap & 454.52 & 809.86 & 1107.67 & 1400.11 & 1526.57 & 1491.65 & 1283.18 & 1004.97 & 732.79 & 392.40 & \\
\hline Liquidity & -1.37 & -0.90 & -0.41 & -0.81 & -0.61 & -0.66 & -0.63 & -0.54 & -0.66 & -1.07 & \\
\hline MKT beta & $\begin{array}{c}1.12 \\
(37.25)\end{array}$ & $\begin{array}{c}1.09 \\
(48.37)\end{array}$ & $\begin{array}{c}1.02 \\
(61.23)\end{array}$ & $\begin{array}{c}0.96 \\
(56.63)\end{array}$ & $\begin{array}{c}0.98 \\
(65.92)\end{array}$ & $\begin{array}{c}0.99 \\
(59.99)\end{array}$ & $\begin{array}{c}1.02 \\
(58.01)\end{array}$ & $\begin{array}{c}1.01 \\
(58.52)\end{array}$ & $\begin{array}{c}1.02 \\
(51.53)\end{array}$ & $\begin{array}{c}1.09 \\
(40.84)\end{array}$ & $\begin{array}{l}-0.03 \\
(-0.74)\end{array}$ \\
\hline SMB beta & $\begin{array}{c}0.37 \\
(8.02)\end{array}$ & $\begin{array}{l}-0.00 \\
(-0.02)\end{array}$ & $\begin{array}{c}-0.13 \\
(-5.11)\end{array}$ & $\begin{array}{c}-0.16 \\
(-6.03)\end{array}$ & $\begin{array}{l}-0.09 \\
(-4.21)\end{array}$ & $\begin{array}{l}-0.15 \\
(-6.10)\end{array}$ & $\begin{array}{c}-0.11 \\
(-4.19)\end{array}$ & $\begin{array}{l}-0.00 \\
(-0.02)\end{array}$ & $\begin{array}{c}0.04 \\
(1.20)\end{array}$ & $\begin{array}{c}0.16 \\
(4.06)\end{array}$ & $\begin{array}{c}-0.20 \\
(-3.25)\end{array}$ \\
\hline HML beta & $\begin{array}{c}-0.20 \\
(-4.04)\end{array}$ & $\begin{array}{l}-0.05 \\
(-1.31)\end{array}$ & $\begin{array}{c}0.02 \\
(0.87)\end{array}$ & $\begin{array}{c}-0.02 \\
(-0.80)\end{array}$ & $\begin{array}{c}0.10 \\
(4.22)\end{array}$ & $\begin{array}{c}0.12 \\
(4.40)\end{array}$ & $\begin{array}{c}0.07 \\
(2.60)\end{array}$ & $\begin{array}{c}0.09 \\
(3.27)\end{array}$ & $\begin{array}{l}-0.01 \\
(-0.38)\end{array}$ & $\begin{array}{c}-0.15 \\
(-3.39)\end{array}$ & $\begin{array}{c}0.05 \\
(0.76)\end{array}$ \\
\hline MOM beta & $\begin{array}{c}0.04 \\
(1.64) \\
\end{array}$ & $\begin{array}{c}-0.00 \\
(-0.18)\end{array}$ & $\begin{array}{c}0.02 \\
(1.25)\end{array}$ & $\begin{array}{c}0.01 \\
(1.13)\end{array}$ & $\begin{array}{c}-0.02 \\
(-1.91)\end{array}$ & $\begin{array}{c}-0.00 \\
(-0.17)\end{array}$ & $\begin{array}{c}-0.01 \\
(-0.76)\end{array}$ & $\begin{array}{c}0.01 \\
(0.65) \\
\end{array}$ & $\begin{array}{c}-0.02 \\
(-1.11)\end{array}$ & $\begin{array}{c}-0.01 \\
(-0.46)\end{array}$ & $\begin{array}{c}-0.05 \\
(-1.51) \\
\end{array}$ \\
\hline
\end{tabular}




\section{Table 8}

\section{Alphas of Value-Weighted Portfolios Sorted on Historical Liquidity Betas}

At each year-end between 1967 and 1998, eligible stocks are sorted into 10 portfolios according to historical liquidity betas. The betas are estimated as the slope coefficients on the aggregate liquidity innovation in regressions of excess stock returns on that innovation and the three Fama-French factors. The regressions are estimated using the most recent five years of data, and eligible stocks are defined as ordinary common shares traded on the NYSE, AMEX, or NASDAQ with five years of monthly returns continuing through the current year-end and with stock prices between $\$ 5$ and $\$ 1,000$. The portfolio returns for the 12 post-ranking months are linked across years to form one series of post-ranking returns for each decile. The table reports the decile portfolios' post-ranking alphas, in percent per year. The alphas are estimated as intercepts from the regressions of excess portfolio post-ranking returns on excess market returns (CAPM alpha), on the Fama-French factor returns (Fama-French alpha), and on the Fama-French and momentum factor returns (4-factor alphas). The $t$-statistics are in parentheses.

\begin{tabular}{|c|c|c|c|c|c|c|c|c|c|c|c|}
\hline & 1 & 2 & 3 & 4 & 5 & 6 & 7 & 8 & 9 & 10 & $10-1$ \\
\hline \multicolumn{12}{|c|}{ Jan 1968 - Dec 1999} \\
\hline CAPM alpha & $\begin{array}{c}-2.06 \\
(-1.30)\end{array}$ & $\begin{array}{l}-0.36 \\
(-0.34)\end{array}$ & $\begin{array}{c}0.63 \\
(0.76)\end{array}$ & $\begin{array}{c}0.49 \\
(0.57)\end{array}$ & $\begin{array}{c}0.07 \\
(0.10)\end{array}$ & $\begin{array}{c}0.49 \\
(0.58)\end{array}$ & $\begin{array}{c}1.42 \\
(1.64)\end{array}$ & $\begin{array}{c}1.36 \\
(1.63)\end{array}$ & $\begin{array}{c}-0.02 \\
(-0.02)\end{array}$ & $\begin{array}{c}2.60 \\
(1.96)\end{array}$ & $\begin{array}{c}4.66 \\
(2.36)\end{array}$ \\
\hline Fama-French alpha & $\begin{array}{c}-0.62 \\
(-0.42)\end{array}$ & $\begin{array}{c}-0.09 \\
(-0.08)\end{array}$ & $\begin{array}{c}0.46 \\
(0.57)\end{array}$ & $\begin{array}{c}0.57 \\
(0.68)\end{array}$ & $\begin{array}{c}-0.62 \\
(-0.86)\end{array}$ & $\begin{array}{c}-0.28 \\
(-0.35)\end{array}$ & $\begin{array}{c}0.90 \\
(1.06)\end{array}$ & $\begin{array}{c}0.84 \\
(1.00)\end{array}$ & $\begin{array}{c}0.03 \\
(0.03)\end{array}$ & $\begin{array}{c}3.53 \\
(2.71)\end{array}$ & $\begin{array}{c}4.15 \\
(2.08)\end{array}$ \\
\hline 4-factor alpha & $\begin{array}{l}-1.20 \\
(-0.79)\end{array}$ & $\begin{array}{c}-0.04 \\
(-0.04)\end{array}$ & $\begin{array}{c}0.22 \\
(0.26)\end{array}$ & $\begin{array}{c}0.34 \\
(0.40)\end{array}$ & $\begin{array}{c}-0.29 \\
(-0.40)\end{array}$ & $\begin{array}{c}-0.25 \\
(-0.31)\end{array}$ & $\begin{array}{c}1.05 \\
(1.20)\end{array}$ & $\begin{array}{c}0.71 \\
(0.82)\end{array}$ & $\begin{array}{c}0.29 \\
(0.29)\end{array}$ & $\begin{array}{c}3.67 \\
(2.74)\end{array}$ & $\begin{array}{c}4.87 \\
(2.38)\end{array}$ \\
\hline \multicolumn{12}{|c|}{ Jan 1968 - Dec 1983} \\
\hline CAPM alpha & $\begin{array}{l}-1.10 \\
(-0.46)\end{array}$ & $\begin{array}{c}1.04 \\
(0.70)\end{array}$ & $\begin{array}{c}0.94 \\
(0.79)\end{array}$ & $\begin{array}{c}0.35 \\
(0.27)\end{array}$ & $\begin{array}{c}-0.28 \\
(-0.26)\end{array}$ & $\begin{array}{c}0.46 \\
(0.34)\end{array}$ & $\begin{array}{c}0.09 \\
(0.08)\end{array}$ & $\begin{array}{c}0.83 \\
(0.72)\end{array}$ & $\begin{array}{c}0.33 \\
(0.25)\end{array}$ & $\begin{array}{c}2.51 \\
(1.51)\end{array}$ & $\begin{array}{c}3.62 \\
(1.32)\end{array}$ \\
\hline Fama-French alpha & $\begin{array}{c}-1.24 \\
(-0.53)\end{array}$ & $\begin{array}{c}2.32 \\
(1.56)\end{array}$ & $\begin{array}{c}1.66 \\
(1.41)\end{array}$ & $\begin{array}{c}1.53 \\
(1.21)\end{array}$ & $\begin{array}{l}-1.05 \\
(-0.98)\end{array}$ & $\begin{array}{l}-0.49 \\
(-0.38)\end{array}$ & $\begin{array}{c}-0.06 \\
(-0.05)\end{array}$ & $\begin{array}{c}-0.07 \\
(-0.06)\end{array}$ & $\begin{array}{c}0.17 \\
(0.13)\end{array}$ & $\begin{array}{c}1.61 \\
(1.01)\end{array}$ & $\begin{array}{c}2.85 \\
(1.01)\end{array}$ \\
\hline 4-factor alpha & $\begin{array}{c}-3.74 \\
(-1.58)\end{array}$ & $\begin{array}{c}1.50 \\
(0.96)\end{array}$ & $\begin{array}{c}0.87 \\
(0.71)\end{array}$ & $\begin{array}{c}0.86 \\
(0.66)\end{array}$ & $\begin{array}{c}-0.20 \\
(-0.18)\end{array}$ & $\begin{array}{c}0.21 \\
(0.16)\end{array}$ & $\begin{array}{c}0.59 \\
(0.47)\end{array}$ & $\begin{array}{c}-0.18 \\
(-0.15)\end{array}$ & $\begin{array}{c}0.59 \\
(0.43)\end{array}$ & $\begin{array}{c}1.64 \\
(0.98)\end{array}$ & $\begin{array}{c}5.38 \\
(1.86)\end{array}$ \\
\hline \multicolumn{12}{|c|}{ Jan 1984 - Dec 1999} \\
\hline CAPM alpha & $\begin{array}{c}-2.79 \\
(-1.31)\end{array}$ & $\begin{array}{l}-1.63 \\
(-1.04)\end{array}$ & $\begin{array}{c}0.21 \\
(0.18)\end{array}$ & $\begin{array}{c}0.40 \\
(0.36)\end{array}$ & $\begin{array}{c}0.37 \\
(0.36)\end{array}$ & $\begin{array}{c}0.23 \\
(0.23)\end{array}$ & $\begin{array}{c}3.12 \\
(2.51)\end{array}$ & $\begin{array}{c}1.70 \\
(1.40)\end{array}$ & $\begin{array}{c}-0.11 \\
(-0.08)\end{array}$ & $\begin{array}{c}2.70 \\
(1.28)\end{array}$ & $\begin{array}{c}5.49 \\
(1.90)\end{array}$ \\
\hline Fama-French alpha & $\begin{array}{c}0.03 \\
(0.02)\end{array}$ & $\begin{array}{c}-2.04 \\
(-1.29)\end{array}$ & $\begin{array}{c}-0.60 \\
(-0.53)\end{array}$ & $\begin{array}{c}-0.33 \\
(-0.30)\end{array}$ & $\begin{array}{c}-0.40 \\
(-0.40)\end{array}$ & $\begin{array}{c}-0.55 \\
(-0.59)\end{array}$ & $\begin{array}{c}2.21 \\
(1.83)\end{array}$ & $\begin{array}{c}1.50 \\
(1.22)\end{array}$ & $\begin{array}{c}-0.11 \\
(-0.07)\end{array}$ & $\begin{array}{c}4.41 \\
(2.20)\end{array}$ & $\begin{array}{c}4.38 \\
(1.54)\end{array}$ \\
\hline 4-factor alpha & $\begin{array}{c}0.57 \\
(0.30) \\
\end{array}$ & $\begin{array}{l}-1.50 \\
(-0.94) \\
\end{array}$ & $\begin{array}{c}-0.50 \\
(-0.44)\end{array}$ & $\begin{array}{c}-0.28 \\
(-0.25)\end{array}$ & $\begin{array}{c}-0.39 \\
(-0.38) \\
\end{array}$ & $\begin{array}{c}-0.87 \\
(-0.93) \\
\end{array}$ & $\begin{array}{c}2.06 \\
(1.68) \\
\end{array}$ & $\begin{array}{c}1.35 \\
(1.08) \\
\end{array}$ & $\begin{array}{c}0.02 \\
(0.01) \\
\end{array}$ & $\begin{array}{c}4.55 \\
(2.23) \\
\end{array}$ & $\begin{array}{c}3.98 \\
(1.38)\end{array}$ \\
\hline
\end{tabular}




\section{Table 9}

\section{Portfolios Sorted on Market Capitalization}

At each year-end between 1962 and 1998, eligible stocks are sorted into 10 portfolios according to market capitalization. Eligible stocks are defined as ordinary common shares traded on the NYSE, AMEX, or NASDAQ with stock prices between $\$ 5$ and $\$ 1,000$. The breakpoints for the sort are based on all eligible stocks, so that all decile portfolios contain approximately the same number of stocks in each month. The portfolio returns for the 12 post-ranking months are linked across years to form one series of post-ranking returns for each decile. Panel A reports the time-series averages of the deciles portfolios' market capitalization and liquidity, obtained by averaging the corresponding measures across the stocks within each decile. Panels B and C report the decile portfolios' post-ranking liquidity betas, estimated by regressing excess portfolio returns on the aggregate liquidity innovation and the Fama-French factors. Also reported are the portfolios' alphas, estimated as intercepts from the regressions of excess portfolio post-ranking returns on the Fama-French and momentum factor returns. The $t$-statistics are in parentheses. All statistics are calculated over the period January 1963 through December 1999.

\begin{tabular}{|c|c|c|c|c|c|c|c|c|c|c|c|}
\hline & 1 & 2 & 3 & 4 & 5 & 6 & 7 & 8 & 9 & 10 & $1-10$ \\
\hline \multicolumn{12}{|c|}{ Panel A. General properties } \\
\hline Market cap & 10.19 & 20.68 & 33.12 & 49.76 & 74.79 & 114.29 & 184.55 & 329.79 & 731.18 & 4696.50 & \\
\hline Liquidity & -4.08 & -3.59 & -1.71 & -1.42 & -1.11 & -0.71 & -0.44 & -0.21 & -0.10 & -0.02 & \\
\hline \multicolumn{12}{|c|}{ Panel B. Return-based measures for equal-weighted portfolios } \\
\hline Liquidity beta & $\begin{array}{c}4.73 \\
(2.18)\end{array}$ & $\begin{array}{c}4.22 \\
(2.64)\end{array}$ & $\begin{array}{c}2.61 \\
(1.89)\end{array}$ & $\begin{array}{c}0.43 \\
(0.40)\end{array}$ & $\begin{array}{c}0.82 \\
(0.79)\end{array}$ & $\begin{array}{c}0.06 \\
(0.07)\end{array}$ & $\begin{array}{c}-0.25 \\
(-0.28)\end{array}$ & $\begin{array}{c}-1.29 \\
(-1.23)\end{array}$ & $\begin{array}{c}-0.63 \\
(-0.63)\end{array}$ & $\begin{array}{c}0.59 \\
(0.80)\end{array}$ & $\begin{array}{c}4.14 \\
(1.75)\end{array}$ \\
\hline 4-factor alpha & $\begin{array}{c}3.15 \\
(2.34)\end{array}$ & $\begin{array}{c}0.47 \\
(0.48)\end{array}$ & $\begin{array}{c}-0.45 \\
(-0.55)\end{array}$ & $\begin{array}{c}-1.48 \\
(-2.34)\end{array}$ & $\begin{array}{c}-1.42 \\
(-2.27)\end{array}$ & $\begin{array}{c}-1.83 \\
(-3.10)\end{array}$ & $\begin{array}{c}-0.70 \\
(-1.24)\end{array}$ & $\begin{array}{c}-1.40 \\
(-2.12)\end{array}$ & $\begin{array}{c}-1.04 \\
(-1.65)\end{array}$ & $\begin{array}{c}-0.68 \\
(-1.48)\end{array}$ & $\begin{array}{c}3.83 \\
(2.59)\end{array}$ \\
\hline \multicolumn{12}{|c|}{ Panel C. Return-based measures for value-weighted portfolios } \\
\hline Liquidity beta & $\begin{array}{c}5.26 \\
(2.57)\end{array}$ & $\begin{array}{c}3.84 \\
(2.46)\end{array}$ & $\begin{array}{c}1.95 \\
(1.52)\end{array}$ & $\begin{array}{c}-0.42 \\
(-0.43)\end{array}$ & $\begin{array}{c}0.34 \\
(0.37)\end{array}$ & $\begin{array}{c}-1.13 \\
(-1.25)\end{array}$ & $\begin{array}{c}-0.48 \\
(-0.54)\end{array}$ & $\begin{array}{c}-1.02 \\
(-1.04)\end{array}$ & $\begin{array}{c}-1.60 \\
(-1.66)\end{array}$ & $\begin{array}{c}0.17 \\
(0.67)\end{array}$ & $\begin{array}{c}5.09 \\
(2.51)\end{array}$ \\
\hline 4-factor alpha & $\begin{array}{c}3.01 \\
(2.34)\end{array}$ & $\begin{array}{c}1.09 \\
(1.12)\end{array}$ & $\begin{array}{c}0.57 \\
(0.71)\end{array}$ & $\begin{array}{c}-0.67 \\
(-1.07)\end{array}$ & $\begin{array}{c}-0.75 \\
(-1.30)\end{array}$ & $\begin{array}{c}-0.91 \\
(-1.64)\end{array}$ & $\begin{array}{c}-0.33 \\
(-0.61)\end{array}$ & $\begin{array}{c}-1.05 \\
(-1.73)\end{array}$ & $\begin{array}{c}-0.81 \\
(-1.34)\end{array}$ & $\begin{array}{c}0.50 \\
(3.14)\end{array}$ & $\begin{array}{c}2.51 \\
(1.96)\end{array}$ \\
\hline
\end{tabular}




\section{Table 10}

\section{Liquidity-Risk Spreads and Investment Opportunities}

Each row of Panel A reports the ex-post tangency portfolio weights (in percent) as well as the ex-post monthly Sharpe ratio of the tangency portfolio in the given asset universe. The assets available for investment are various subsets of six traded factors. This set comprises the Fama-French factors MKT, SMB, and HML, a momentum factor MOM, and two liquidity-risk spreads, both of which go long decile 10, containing the stocks with the highest predicted liquidity betas, and short decile 1, containing the stocks with the lowest betas. Each leg of the spread is value-weighted in $\mathrm{LIQ}^{V}$ and equally-weighted in $\mathrm{LIQ}^{E}$. Panel B reports the alphas (in percent per year) of the momentum portfolio with respect to the factors listed in the row label. The $t$-statistics are in parentheses.

Panel A. Weights in the ex-post tangency portfolio, Jan 1966 - Dec 1999

\begin{tabular}{ccccccc} 
MKT & SMB & HML & MOM & $\mathrm{LIQ}^{V}$ & $\mathrm{LIQ}^{E}$ & Sharpe ratio \\
\hline 100.00 & - & - & - & - & - & 0.12 \\
35.08 & 5.83 & 59.10 & - & - & - & 0.22 \\
20.05 & 16.07 & 43.03 & 20.85 & - & - & 0.33 \\
22.34 & 18.77 & 36.41 & - & 22.49 & - & 0.31 \\
17.32 & 22.33 & 29.10 & - & - & 31.25 & 0.40 \\
17.70 & 20.62 & 34.23 & 11.86 & 15.59 & - & 0.37 \\
15.88 & 22.51 & 29.56 & 6.47 & - & 25.58 & 0.42
\end{tabular}

Panel B. Alphas from the regression of momentum on portfolios listed

Jan 1966 - Dec $1999 \quad$ Jan 1966 - Dec $1982 \quad$ Jan 1983 - Dec 1999

\begin{tabular}{lccc}
\hline MKT,SMB,HML & 16.30 & 21.65 & 11.10 \\
& $(4.85)$ & $(4.53)$ & $(2.29)$ \\
MKT,SMB,HML,LIQ $^{V}$ & 13.89 & 19.46 & 8.03 \\
& $(4.09)$ & $(4.04)$ & $(1.63)$ \\
MKT,SMB,HML,LIQ $^{E}$ & 8.41 & 16.11 & -1.29 \\
& $(2.55)$ & $(3.35)$ & $(-0.28)$
\end{tabular}




\section{References}

Amihud, Yakov, 2000, Illiquidity and stock returns: Cross-section and time-series effects, working paper, NYU.

Amihud, Y., and H. Mendelson, 1986, Asset pricing and the bid-ask spread, Journal of Financial Economics 17, 223-249.

Amihud, Yakov, Haim Mendelson, and Robert Wood, 1990, Liquidity and the 1987 stock market crash, Journal of Portfolio Management, Spring, 65-69.

Brennan, Michael J., Tarun Chordia, and Avanindhar Subrahmanyam, 1998, Alternative factor specifications, security characteristics, and the cross-section of expected stock returns, Journal of Financial Economics 49, 345-373.

Brennan, Michael J., and Avanindhar Subrahmanyam, 1996, Market microstructure and asset pricing: On the compensation for illiquidity in stock returns, Journal of Financial Economics 41, 441-464.

Campbell, John, Sanford J. Grossman, and Jiang Wang, 1993, Trading volume and serial correlation in stock returns, Quarterly Journal of Economics 108, 905-939.

Chordia, Tarun, Richard Roll, and Avanidhar Subrahmanyam, 2000a, Commonality in liquidity, Journal of Financial Economics 56, 3-28.

Chordia, Tarun, Richard Roll, and Avanidhar Subrahmanyam, 2000b, Market liquidity and trading activity, Journal of Finance, forthcoming.

Chordia, Tarun, Richard Roll, and Avanidhar Subrahmanyam, 2001, Order imbalance, liquidity, and market returns, Journal of Financial Economics, forthcoming.

Chordia, Tarun, Avanindhar Subrahmanyam, and V. Ravi Anshuman, 2000, Trading activity and expected stock returns, Journal of Financial Economics, forthcoming.

Constantinides, George, 1986, "Capital market equilibrium with transaction costs", Journal of Political Economy 94, 842-862.

Cox, John C., Jonathan E. Ingersoll, Jr., and Stephen A. Ross, 1985, An intertemporal general equilibrium model of asset prices, Econometrica 53, 363-384.

Datar, Vinay T., Narayan Y. Naik, and Robert Radcliffe, 1998, Liquidity and asset returns: An alternative test, Journal of Financial Markets 1, 203-219.

The Economist, 1999, When the sea dries up, September 25, page 93.

Eisfeldt, Andrea L., 2001, "Endogenous liquidity in asset markets", working paper, Northwestern University.

Fama, Eugene F. and Kenneth R. French, 1993, Common risk factors in the returns on stocks and bonds, Journal of Financial Economics 33, 3-56. 
Fama, Eugene F. and Kenneth R. French, 1996, Multifactor explanations of asset pricing anomalies, Journal of Finance 51, 55-84.

Fiori, Filippo, Liquidity premia in the equity markets: An investigation into the characteristics of liquidity and trading activity, working paper, University of Chicago.

Foster, F. Douglas, and S. Viswanathan, 1993, Variations in trading volume, return volatility, and trading costs: Evidence on recent price formation models, Journal of Finance 48, $187-211$.

Gibbons, Michael R., Stephen A. Ross, and Jay Shanken, 1989, A test of the efficiency of a given portfolio, Econometrica 57, 1121-1152.

Grinblatt, Mark, and Sheridan Titman, 1987, The relation between mean-variance efficiency and arbitrage pricing, Journal of Business 60, 97-112.

Grossman, Sanford J. and Merton H. Miller, 1988, Liquidity and market structure, Journal of Finance 43, 617-633.

Hansen, Lars P., 1982, Large Sample Properties of Generalized Method of Moments Estimators, Econometrica 50, 1029-1054.

Hasbrouck, Joel, 1991, Measuring the information content of stock trades, Journal of Finance 46, 179-207.

Hasbrouck, Joel, and Duane J. Seppi, 2000, Common factors in prices, order flows, and liquidity, Journal of Financial Economics, forthcoming.

Heaton, John, and Deborah J. Lucas, 1996, "Evaluating the effects of incomplete markets on risk sharing and asset pricing", Journal of Political Economy 104, 443-487.

Holmström, Bengt, and Jean Tirole, 2001, "LAPM: A liquidity-based asset pricing model", Journal of Finance, forthcoming.

Huang, Ming, 2001, "Liquidity shocks and equilibrium liquidity premia", working paper, Stanford University.

Huberman, Gur, and Dominika Halka, 1999, Systematic liquidity, working paper, Columbia University.

Huberman, Gur, Shmuel Kandel, and Robert F. Stambaugh, 1987, Mimicking portfolios and exact arbitrage pricing," Journal of Finance 42, 1-9.

Jegadeesh, Narasimhan, and Sheridan Titman, 1993, Returns to buying winners and selling losers: Implications for stock market efficiency, Journal of Finance 48, 65-91.

Jobson, J.D., and Bob Korkie, 1982, Potential performance and tests of portfolio efficiency, Journal of Financial Economics 10, 433-466.

Jobson, J.D., and Bob Korkie, 1985, Some tests of linear asset pricing with multivariate normality, Canadian Journal of Administrative Sciences 2, 114-138. 
Jones, Charles M., 2000, A century of stock market liquidity and trading costs, working paper, Columbia University.

Lee, Charles M.C., and Bhaskaran Swaminathan, 1998, Price momentum and trading volume, working paper, Cornell University.

Llorente, Guillermo, Roni Michaely, Gideon Saar, and Jiang Wang, 2001, Dynamic volumereturn relation of individual stocks, working paper, Universidad Autonoma de Madrid.

Lo, Andrew W., Harry Mamaysky, and Jiang Wang, 2001, "Asset prices and trading volume under fixed transaction costs", working paper, MIT.

Lo, Andrew W., and Jiang Wang, 2000, Trading volume: Definitions, data analysis, and implications of portfolio theory, Review of Financial Studies 13, 257-300.

Merton, Robert C., 1973, An intertemporal capital asset pricing model, Econometrica 41, $867-887$.

Shanken, Jay, 1990, Intertemporal asset pricing: An empirical investigation, Journal of Econometrics 45, 99-120.

Vayanos, Dimitri, 1998, "Transaction costs and asset prices: A dynamic equilibrium model", Review of Financial Studies 11, 1-58.

Wang, Jiang, 1994, A model of competitive stock trading volume, Journal of Political Economy 102, 127-168. 